\title{
Goal-Directed Fluid Therapy during Major Abdominal Surgery
}

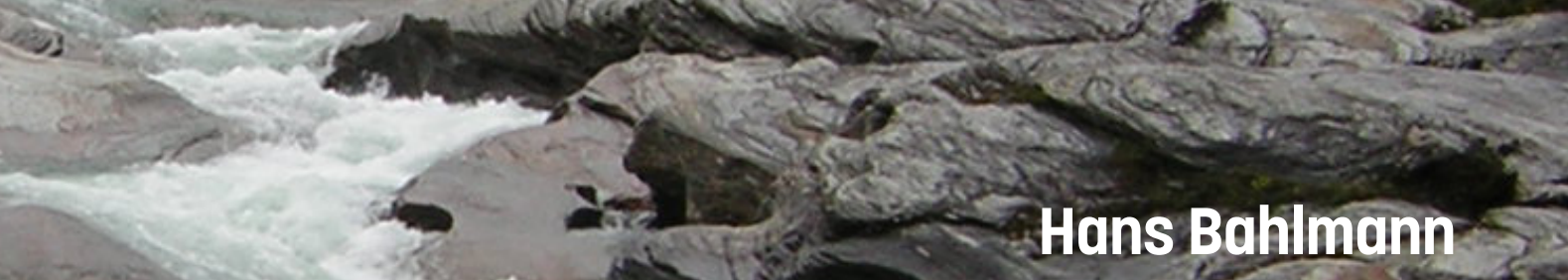




\title{
Goal-directed fluid therapy during major abdominal surgery
}

\author{
Hans Bahlmann
}

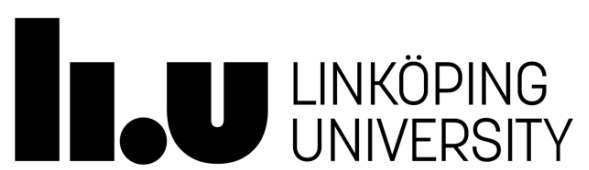

Department of Medical and Health Sciences

Linköping University, Sweden

Linköping 2019 
(CHans Bahlmann, 2019

Cover: Låhdejåkkå, Padjelanta National Park, Sweden Image by the author

Published articles have been reprinted with permission from the copyright holder.

Quotes:

Page 24 U2, A Beautiful day. Music and lyrics: Larry Mullen/Adam Clayton/Paul Hewson/Dave Evans. (C) Universal Music Publishing International BV. Nordic and Baltic rightsholder: Universal Music Publishing AB. Reprinted with permission from Gehrmans Musikförlag AB.

Page 32 The Eriksson twins. https://www.youtube.com/watch?v= cb7RrbowV-Q. With permission from Olle Sundin.

Page 43 Sir Robert Giffen, from The Economic Journal 1892;2:209-238. With permission from The Royal Economic Society.

Page 43 Bahá'u'lláh, Tablets of Bahá'u'lláh Revealed after the Kitáb-iAqdas, pp. 51-52. Copyright (C) Bahá'í International Community. Page 61 Nescio, Amsterdam Stories, p 57. New York Review of Books. Copyright (C) Damion Searls. With permission from Damion Searls.

Printed in Sweden by LiU-Tryck, Linköping, Sweden, 2019.

ISBN 978-91-7685-123-4

ISSN 0345-0082 


\section{CONTENTS}

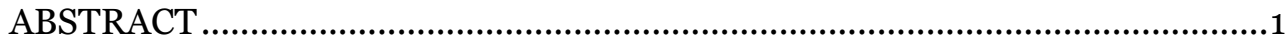

SVENSK SAMMANFATTNING ……............................................................. 3

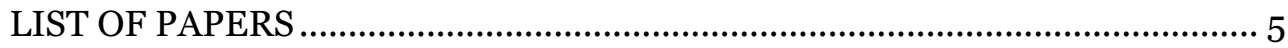

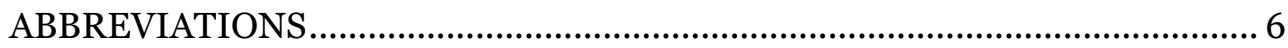

ACKNOWLEDGEMENTS …....................................................................... 7

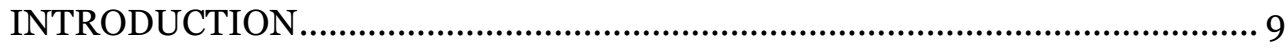

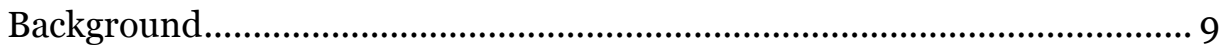

Possible goals for goal-directed fluid therapy ................................................13

Measurement devices...................................................................................17

Preoperative dehydration.............................................................................21

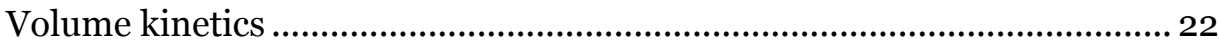

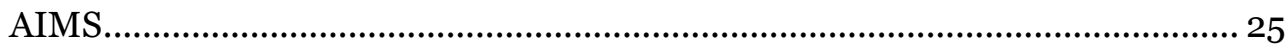

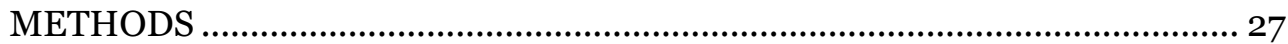

Ethical considerations and registration........................................................ 27

Patient selection and inclusion ................................................................... 27

General patient management ........................................................................ 27

Interventions and key measurements ....................................................... 28

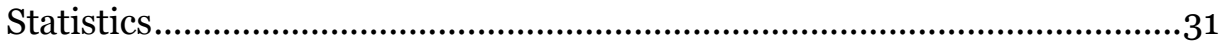

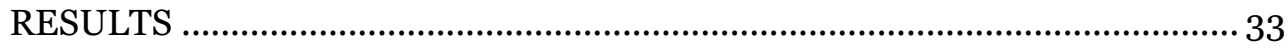

Studies I-III ............................................................................................. 33

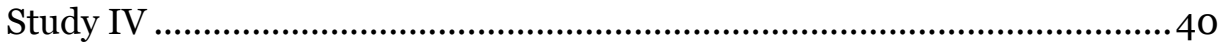

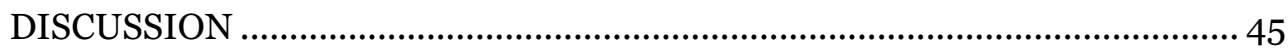

Stroke volume optimisation ......................................................................... 45

Dynamic parameters …………………........................................................... 49

Limited agreement between measuring devices .......................................... 50

Specific challenges for PVI, oesophageal Doppler and FloTrac. …............. 50

Besides fluids: inotropes and vasoconstrictors ............................................. 52

Preoperative dehydration............................................................................ 53

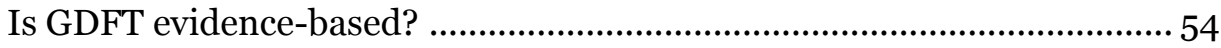

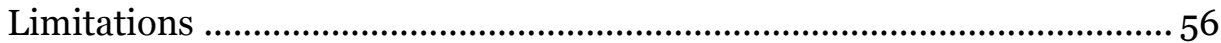

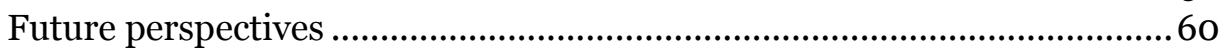


CONCLUSIONS ............................................................................................ 63

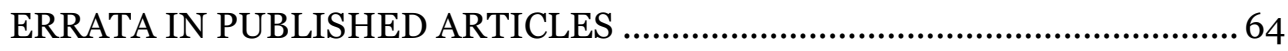

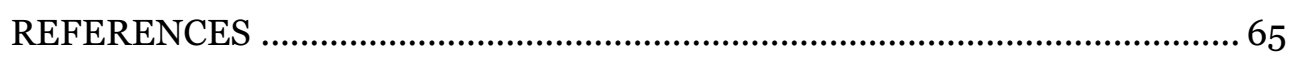

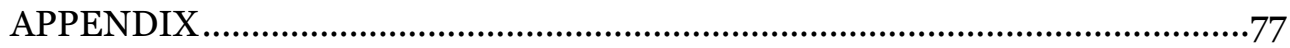

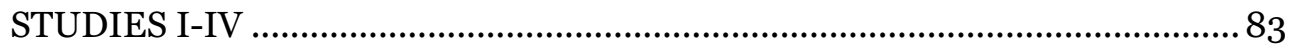




\section{ABSTRACT}

Background: Both hypo- and hypervolemia increase the risk for postoperative complications after major abdominal surgery. Fluid needs vary amongst patients depending on differences in preoperative dehydration, intraoperative physiology and surgical characteristics. Goal-directed fluid therapy (GDFT) aims to target the right amount of fluid administration in each patient by evaluating the effect of fluid boluses on haemodynamic parameters such as stroke volume. It has been shown to reduce postoperative morbidity and is generally recommended for high-risk surgery. The overall aim of this thesis was to evaluate whether more simple devices for GDFT result in clinical benefit, thus facilitating the application of GDFT in more patients.

Aim: To compare performance and clinical benefit of pleth variability index (PVI), a non-invasive, easy-to-use device for GDFT, with the reference method of oesophageal Doppler; to evaluate methods for measuring preoperative dehydration and its effect on fluid handling by the body; and to confirm the expected clinical benefits of GDFT in patients undergoing oesophageal resection, a high risk procedure.

Methods: In Studies I-III 150 patients scheduled for open abdominal surgery of at least 2 hrs were randomised to GDFT with either PVI or oesophageal Doppler. In the first half of the cohort, both monitors were connected to compare intraoperative performance. In 30 patients preoperative dehydration was analysed. In study IV 64 patients undergoing oesophageal resection were randomised to GDFT using pulse contour analysis or standard treatment.

Results: The concordance between PVI and oesophageal Doppler for indicating the need for and effect of a fluid bolus was low, and both had only limited capacity to predict the effect of a fluid bolus. Both methods resulted in comparable amounts of fluid being administered and similar clinical outcome. Preoperative dehydration was limited but did impact on fluid handling. Patients receiving GDFT during oesophageal resection received more fluid and more dobutamine compared to controls, but this did not result in any clinical benefit. 
Conclusions: There are methodological issues as well as uncertainties about the clinical benefit of GDFT. We cannot recommend a strict application of any GDFT strategy, but suggest that its components should be incorporated in a more encompassing assessment of a patient's fluid needs. The measurement, impact and treatment of preoperative dehydration need to be further clarified.

ISBN 978-91-7685-123-4

ISSN $0345-0082$ 


\section{SVENSK SAMMANFATTNING}

Tillförsel av intravenös vätska är oumbärlig vid en operation som kräver anestesi. Vätska ges för att ersätta vätskeförluster både före och under ingreppet och för att optimera blodflödet. Hur mycket vätska som är optimalt kan dock vara svårt att avgöra, och både för lite och för mycket vätska ökar risken för komplikationer efter operationen.

Ett sätt att hitta den "optimala mängden vätska" är "målstyrd vätskebehandling”, där man utvärderar effekten av vätska på vissa fysiologiska parametrar såsom hjärtats slagvolym. Målstyrd vätskebehandling anses allmänt vara av värde vid större kirurgiska ingrepp, men för att mäta dessa fysiologiska värden krävs dock instrument som inte används rutinmässigt vid anestesi. Därmed erhåller endast få patienter denna behandling.

Avhandlingens mål är

1. att utvärdera ett lättanvänt instrument för målstyrd vätskebehandling som är baserat på en rutinmetod för att mäta blodets syrgassaturation via en fingersensor (pleth variability index (PVI)), jämfört med en äldre, mer omständig metod med en mätslang i matstrupen, som med Doppler princip mäter blodflödet i stora kroppspulsåder (esofagusDoppler). Detta gjordes i en grupp på 150 patienter som lottades till antingen det ena eller det andra instrumentet;

2. att, i en del av patienterna ur den förra gruppen, utvärdera olika sätt att mäta om en patient är intorkad inför en operation, eftersom detta påverkar mängden vätska som behöver ges; och

3. att utvärdera om målstyrd vätskebehandling med ytterligare ett annat instrument, som analyserar formen av tryckvågen i en pulsålder i t.ex. handleden (FloTrac), resulterar i färre komplikationer hos patienter där matstrupen behöver opereras bort på grund av cancer. Detta studerades hos 64 patienter som lottades till målstyrd vätskebehandling eller standardbehandling.

Avhandlingen visar att PVI och esofagusDoppler sällan överensstämmer när det gäller behovet och effekten av vätska, och att båda två har svårt att förutspå effekten av att mer vätska ges. Mängden vätska som gavs under operationen var dock lika i båda grupperna liksom antalet komplikationer efter operation. Intorkning före operation hos dessa patienter var oftast måttlig, men påverkade ändå fördelningen av infunderad 
vätska i kroppen. Slutligen ledde målstyrd vätskebehandling hos patienter som opererades för esofaguscancer till ökad tillförsel av vätska och även av hjärtstärkande läkemedel, utan att ge någon förbättring av förloppet efter operation.

Slutsatsen är att målstyrd vätskebehandling har begränsningar, och att man inte bör styra vätsketillförsel endast baserad på dessa instrument, utan att man bör ta hänsyn till fler faktorer. När det gäller intorkning behöver både dess förekomst, effekter och behandling studeras mera. 


\section{LIST OF PAPERS}

This thesis is based on the following papers, referred to in the text by their Roman numerals.

I. Bahlmann H, Hahn RG, Nilsson L. Agreement between Pleth Variability Index and oesophageal Doppler to predict fluid responsiveness. Acta Anaesthesiol Scand 2016;60:183-192.

II. Hahn RG, Bahlmann H, Nilsson L. Dehydration and fluid volume kinetics before major open abdominal surgery. Acta Anaesthesiol Scand 2014;58:1258-1266.

III. Bahlmann H, Hahn RG, Nilsson L. Pleth variability index or stroke volume optimization during open abdominal surgery: a randomized controlled trial. BMC Anesthesiol 2018;18:115.

IV. Bahlmann H, Halldestam I, Nilsson L. Goal-directed therapy during transthoracic oesophageal resection does not improve outcome: Randomised controlled trial. Eur J Anaesthesiol 2019;36:153-161. 


\section{ABBREVIATIONS}

ASA American Society of Anesthesiologists

BSA body surface area $\left(\mathrm{m}^{2}\right)$

BW body weight $(\mathrm{kg})$

$\mathrm{C}_{\mathrm{a}} \mathrm{O}_{2} \quad$ arterial oxygen content $(\mathrm{ml} / \mathrm{ml})$

CI cardiac index, $\mathrm{CO} / \mathrm{BSA}\left(\mathrm{l} / \mathrm{min} / \mathrm{m}^{2}\right)$

$\mathrm{CO} \quad$ cardiac output $(\mathrm{l} / \mathrm{min})$

CONSORT Consolidated Standards of Reporting Trials

CVP central venous pressure $(\mathrm{mmHg})$

DI dehydration index

$\mathrm{DO}_{2} \quad$ delivery of oxygen to the tissues $(\mathrm{ml} / \mathrm{min})$

ERAS Enhanced Recovery After Surgery

GDFT goal-directed fluid therapy

$\mathrm{Hb}$ haemoglobin

HR heart rate (/min)

IBW ideal body weight $(\mathrm{kg})$

ICU intensive care unit

IQR interquartile range

MAP mean arterial pressure $(\mathrm{mmHg})$

ni non-inferiority

PI perfusion index (\%)

PAC pulmonary artery catheter

PLR passive leg raising

PVI pleth variability index (\%)

ROC receiver operating characteristic

$\mathrm{S}_{\mathrm{cv}} \mathrm{O}_{2} \quad$ central venous saturation (\%)

SD standard deviation

SV $\quad$ stroke volume $(\mathrm{ml})$

SVO stroke volume optimisation

$\mathrm{S}_{\mathrm{v}} \mathrm{O}_{2} \quad$ mixed venous saturation (\%)

SVV stroke volume variation (\%)

$\mathrm{VO}_{2} \quad$ consumption of oxygen by the tissues $(\mathrm{ml} / \mathrm{min})$ 


\section{ACKNOWLEDGEMENTS}

Lena Nilsson, my main supervisor, for being the mother of all supervisors. Kind, attentive, patient, accurate, committed, thoughtful, quickresponding, and always having a solution to obscure challenges posed by Office. We both know it was actually you who did most of the work.

Robert Hahn, my co-supervisor, for the honour of having such an eminent scientist on board, for quick responses and thoughtful reflections on our projects and on issues in the field, both scientific and meta-scientific, and for meaningful short chats during congresses and courses abroad.

Anna Oscarsson-Tibblin, my co-supervisor and head of the department, for meticulous proofreading and for being the solid rock behind it all, giving me peace of mind that whatever what, this project would one day be completed.

Michelle Chew and Christina Eintrei, current and former professors at the department, for believing in this project, providing financial support as well as untiringly increasing the level of scientific activity in the department.

Martin Golster and Eva-Lena Zetterlund, former heads of the department, for allowing research time to be spent despite at times limited human resources on the floor.

Kerstin Metcalf, my first-line boss, for clearly showing your appreciation of and interest in implementing modern recommendations in the field of perioperative fluid management.

Research nurses Helén Didriksson, Gunilla Gagnö, Susanne Lind, Lena Sundin, Susanne Öster and Anette Dahlkvist (Örebro), for such diligent and accurate work, for being such pleasant company and always goodhumoured, even when doing a urine analysis at six AM.

Ingvar Halldestam, oesofagogastric surgeon and co-author, for your enthusiasm for Study IV and the time you spent on it, despite a heavy clinical work load.

Mats Fredriksson, statistician, for highly significant statistical advice. 
Rebecca Ahlstrand and Alex De León, colleagues at Örebro University Hospital, for assisting in Study IV.

All my fellow anaesthetists at the department, who, after taking care of patients the whole day in my place, wondered what I was doing when they saw me behind the computer at the $14^{\text {th }}$ floor (or when the office was empty, again).

All anaesthesia nurses at "section K" for always meeting me with a smile when I entered the OR with yet another of "my machines" (perhaps I should say "almost always"?).

All patients who consented to be included in the studies, for spending time to read the obligatory paperwork and consenting to participate, notwithstanding the fact that most of them had life-threatening malignant disease and all of them were preparing themselves for a major surgical procedure. "Of course I will participate, if it can help someone else" was something often to be heard. Many of them have not survived their disease, but their generosity and benevolence will always be remembered.

Bengt Robertson (†2008), surfactant pioneer at the Karolinska Institute, his staff, friends and family, for opening so many doors for me: to Sweden, to research, and to the Stockholm Archipelago.

Hugo Lagercrantz, senior professor of paediatrics at the Karolinska Institute, for opening for me the doors to clinical work in Sweden, and for making that call to Handelsbanken in Mörby Centrum to get me a bank account without having a personal identity number ....

Willy and Fred and Renie, for giving me such a privileged start in life.

Emma and Moa, my two miracles, for allowing me to witness the wonder of life.

Kerstin, my Deodonata, I am so grateful that our paths literally crossed in the rainy mountains of Jämtland. Thank you for taking care of our family and expanding my life. I love you. 


\section{INTRODUCTION}

\section{Background}

For the human organism, life and function are dependent on functioning cells. Since most cells in the human body have no direct access to the environment outside the body, functioning cells are dependent on being surrounded by a fluid, the interstitial fluid, which provides them with substances they need, such as oxygen and glucose, and also removes substances which are by-products of cellular metabolic processes, e.g. carbon dioxide. Replenishing the interstitial fluid with needed ingredients and removing by-products is done by specialised organs in the body, sometimes on quite a distance from the actual cell and the fluid surrounding it. Therefore the body is equipped with a transport system, henceforth called circulation, where the heart pumps around blood which passes specialised organs for the uptake and removal of specific substances, and equilibrates with the interstitial fluid elsewhere in the body.

An adequate flow of blood is dependent on 1. a sufficient volume of blood, consisting of both oxygen-transporting red blood cells and plasma, enough to fill the vascular bed and the heart; 2. functioning blood vessels enabling the blood to flow from the tissues to the heart (venous return), and after being pumped out, to reach the smallest blood vessels, capillaries, and there equilibrate with the interstitial fluid, as well as causing some resistance to flow leading to adequate blood pressure; and 3. a heart that pumps out an adequate amount of blood with every heart beat (stroke volume SV) a sufficient number of times per minute (heart rate $\mathrm{HR}$ ), resulting in an adequate flow of blood (cardiac output $\mathrm{CO}$ ). The product of $\mathrm{CO}(\mathrm{ml} / \mathrm{min})$ and arterial oxygen content $\mathrm{C}_{\mathrm{a}} \mathrm{O}_{2}(\mathrm{ml} / \mathrm{ml})$ equals $\mathrm{DO}_{2}$, the amount of oxygen delivered to the body $(\mathrm{ml} / \mathrm{min})$.

Clearly, a well-regulated cellular environment concerning e.g. acidity, oxygen content and osmolarity, sometimes referred to as homeostasis, is essential for human life. A major part of the body's autonomic systems is therefore devoted to this task. ${ }^{1}$ For instance, when the amount of interstitial fluid decreases a sensation of thirst occurs which leads to intake of water entering the intestines. This water is then absorbed and enters the bloodstream and later, by diffusion and leakage through the capillary wall, the interstitial fluid correcting the fluid deficit. Another example is that during acute blood loss venous blood vessels contract to mitigate a 
fall in venous return caused by a decreased blood volume; simultaneously cardiac contractility and heart rate increase, and arterial blood vessels contract to compensate for a decrease in blood pressure caused by the diminished cardiac output.

Disturbances of the cellular environment can be caused by several factors: 1. lack of access to needed substances, such as starvation or suffocation; 2. malfunctioning of specialised organs responsible for uptake, production and/or disposal of certain substances, such as pneumonia or renal failure; 3. malfunctioning of the circulatory system caused by e.g. lack of blood or cardiac malfunctioning; and 4. (uncommon) primary cellular malfunctioning overwhelming extracellular compensatory mechanisms, e.g. certain intoxications or inborn metabolic diseases.

Surgery, and the anaesthesia and analgesia required to endure it, poses a complex challenge to the cellular environment, added to the challenges already caused by the primary disease process necessitating the surgical procedure, e.g. ileus, as well as concomitant disease processes, e.g. coronary artery disease:

1. Surgery inevitably causes tissue damage which leads to an inflammatory response. Inflammation has developed during evolution to enable the body to deal with invading microorganisms, however it entails amongst others an increase in capillary permeability, leading to an increased amount of interstitial fluid and a decreased volume of blood.

2. Surgery entails blood loss ranging from either negligible amounts to major haemorrhages equalling several blood volumes.

3. In order to decrease the risk of aspiration of gastric contents, patients scheduled for surgery are not allowed to eat and/or drink for a variable length of time before the procedure. This leads to dehydration, or in some cases aggravates dehydration already in place.

4. Anaesthetic drugs weaken autonomic compensatory mechanisms such as increase in heart rate as a response to hypovolemia, and usually cause vasodilation and varying degrees of cardiac malfunctioning.

5. Anaesthesia and the surgical procedure directly influence specialised homeostatic organs such as the lungs, kidney and intestines.

A decrease in the amount of body fluid, either cellular, interstitial or intravascular, is common in surgical (or for that matter even many medical) patients, and a frequent cause of disability or death in patients if not treated. Since the normal route for fluids into the body, the gastrointestinal system, is often dysfunctional or inadequate during severe disease, the ability to infuse fluids directly into the (venous) blood, bypassing the in- 
testine, is a major medical landmark, without which modern surgery would be impossible. An intravenous infusion of water and salt (saline) was reported to rescue patients during the cholera epidemics in the early 19th century, and some fifty years later it was reported to be of use in bleeding patients. ${ }^{2} 34$

In the early 2oth century the use of intravenous fluids during surgery became common. It was soon noted that the amounts of fluids that needed to be infused to restore blood volume exceeded measured losses, and experiences during the Korean and Vietnam wars led to the practice of infusions of large volumes of fluid, also during elective surgery. This was done in order to target normal urine production (diuresis) during and after surgery, as well as to compensate for a suspected sequestration of fluid in another non-functional compartment, the so-called third space. Excess fluids were thought to impose no major risk.

First at the beginning of the 21th century it was shown that large amounts of intravenous fluids are harmful in surgical patients. 5 One suggested reason was that intravenous fluids could lead to an increased amount of interstitial fluid (oedema), especially in injured tissue, which hinders the delivery of oxygen from the capillaries to the cells. ${ }^{6}$ However it was also noted that too little fluid was detrimental. ${ }^{8}$ Therefore the idea arose to guide the amount of fluid based on physiological parameters and thus to find the right balance between fluid overload and too little fluid (Fig 1). This is referred to as goal-directed fluid therapy.

Figure 1. The optimal amount of fluid.

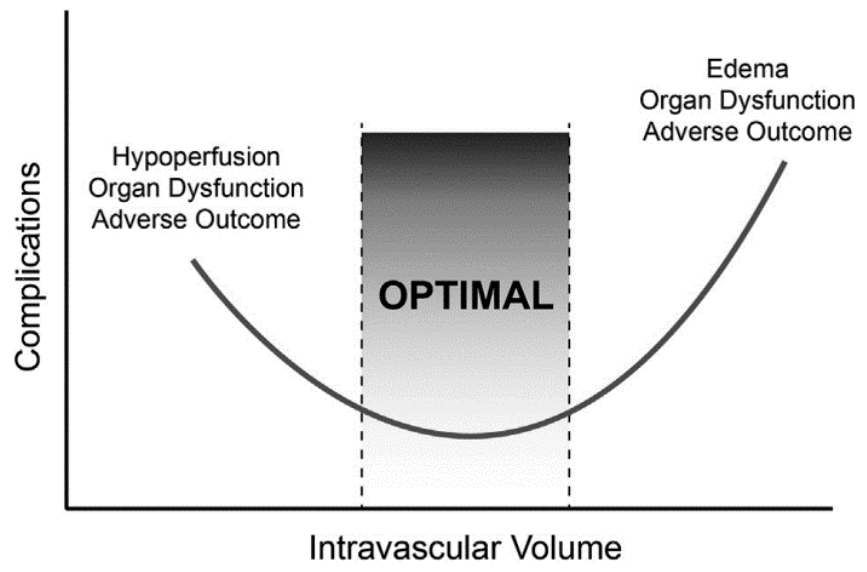

Reprinted from Best Practice \& Research Clinical Anaesthesiology 2014;28. Miller TE, Raghunathan K, Gan TJ. State-of-the-art fluid management in the operating room, page 261-273. Copyright (2014), with permission from Elsevier. 
The concept that there exists an optimum or "sweet spot" (or perhaps "sweet range") in fluid administration is supported by recent observations in large surgical cohorts showing a clear association between both upper and lower limits of fluid administration and a complicated postoperative course (Fig 2). 9

Figure 2. Correlation between amount of perioperative fluid and surgical outcome.
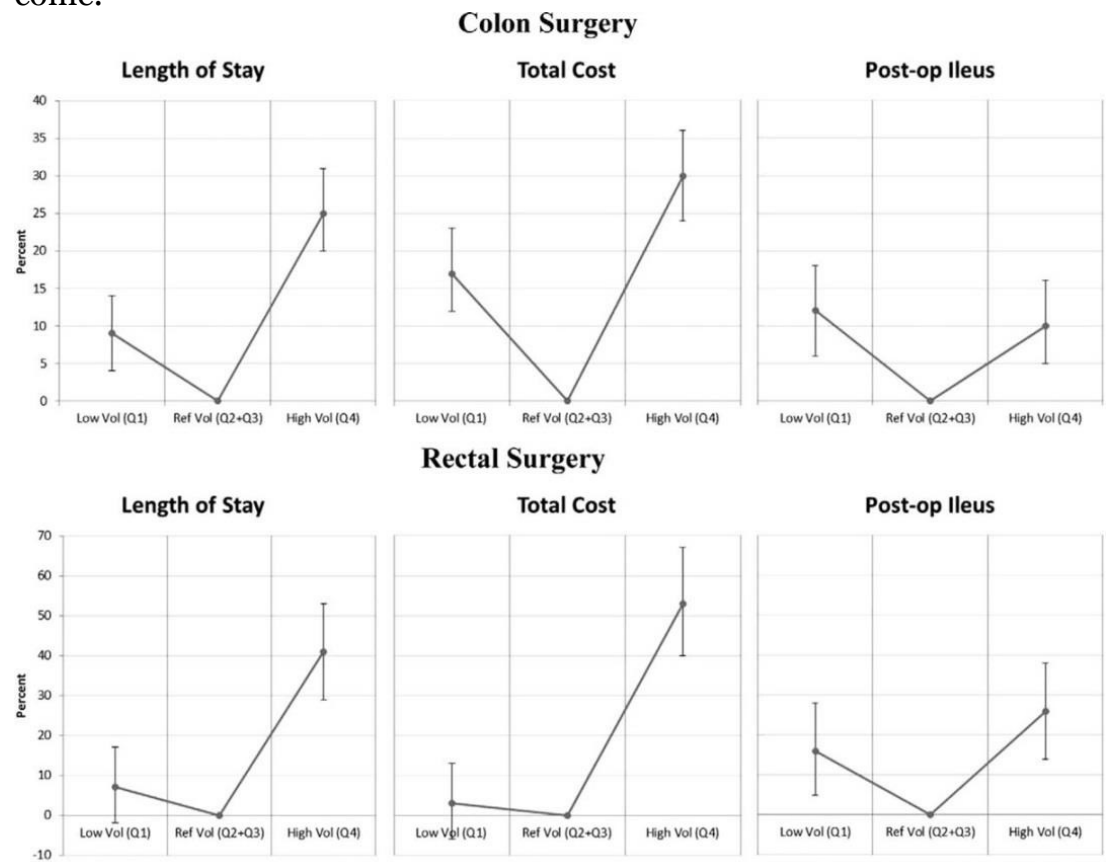

\section{Rectal Surgery}
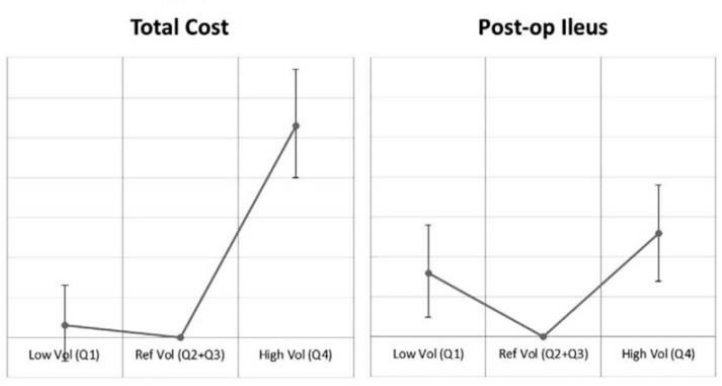

Hip/Knee Surgery
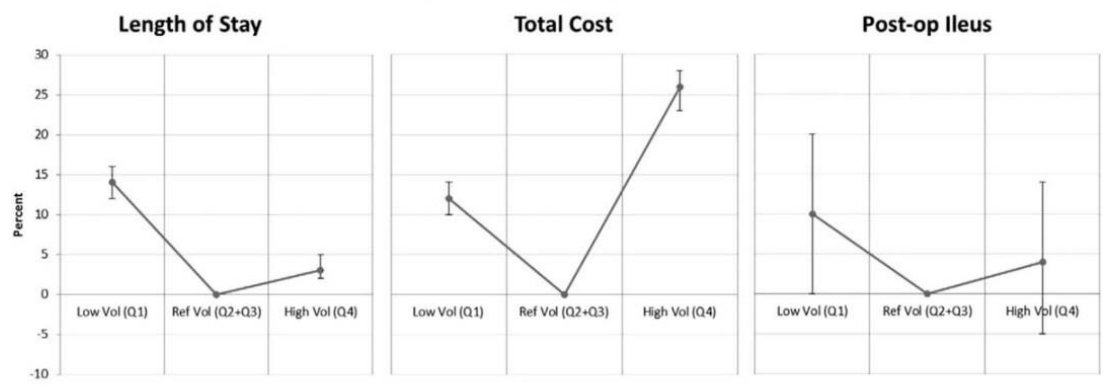

Reprinted from Thacker JK, Mountford WK, Ernst FR, Krukas MR, Mythen MM. Perioperative Fluid Utilization Variability and Association With Outcomes: Considerations for Enhanced Recovery Efforts in Sample US Surgical Populations. Ann Surg 2016;263:502-510.

https://journals.lww.com/annalsofsurgery/Pages/default.aspx. With permission from Wolters Kluwer. 
The importance of aiming for the right amount of fluid is probably dependent on the type of surgical procedure. In relatively small surgical procedures such as repair of inguinal hernia or partial mastectomy, with a low risk of serious postoperative complications, less benefit can be expected from goal-directed fluid therapy compared to complex and highly invasive procedures such as oesophageal resection, which carries a high risk of serious postoperative morbidity and even mortality. Thus goaldirected fluid therapy is generally recommended for this type of high risk procedures, even in the absence of formal evaluations. ${ }^{10} 1112$

\section{Possible goals for goal-directed fluid therapy (GDFT)}

\section{Routine clinical parameters}

Easily accessible parameters such as intraoperative arterial blood pressure and heart rate have been shown not to correspond well with the adequacy of intravascular volume. ${ }^{13}$ Central venous pressure (CVP) by itself does not correlate to fluid need, though it is an important parameter determining venous return and thus CO. ${ }^{14}{ }^{15}$ Also diuresis is not suitable to guide fluid titration since intraoperative diuresis is influenced by many other factors apart from fluid status, and targeting reversal of intraoperative oliguria has not been shown to result in a decrease in postoperative renal failure. ${ }^{16} 17$

\section{Lactate}

A by-product of anaerobic metabolism, lactate has been a target of interest in septic patients on the ICU, though the value of this approach has been questioned. ${ }^{18} 19 \mathrm{In}$ abdominal surgery only one study has reported on the primary use of lactate to guide fluid administration. ${ }^{20}$ In our experience, increased lactate values can sometimes be seen due to local tissue ischaemia, e.g. in a piece of bowel being surgically resected, without any other sign of systemic hypoperfusion or hypovolemia. Therefore, infusing fluids solely based on increased lactate values seems not rational.

\section{Central venous saturation}

Mixed venous saturation $\left(\mathrm{S}_{\mathrm{v}} \mathrm{O}_{2}\right)$, which is the saturation of the blood in the pulmonary artery, reflects the balance between oxygen delivery $\left(\mathrm{DO}_{2}\right)$ and consumption $\left(\mathrm{VO}_{2}\right)$ in the body. A value below $70-75 \%$ is usually considered pathological, provided that arterial saturation is normal. ${ }^{21}$ Sampling of mixed venous blood requires a pulmonary catheter; therefore central venous saturation $\left(\mathrm{S}_{\mathrm{cv}} \mathrm{O}_{2}\right)$ is often used as a surrogate measure. 
Whether mixed and central venous saturations are comparable is a matter of debate. ${ }^{22}$ For instance, during general anaesthesia, when the upper body (brain and arms) is inactive, blood from the superior vena cava can be expected to contain more oxygen than blood from the inferior vena cava draining the abdomen, making $\mathrm{S}_{\mathrm{cv}} \mathrm{O}_{2}$ a measurement with low sensitivity but high specificity, since it is usually measured in or nearby the superior vena cava. Furthermore, other measurements are needed to determine whether a low $\mathrm{S}_{\mathrm{cv}} \mathrm{O}_{2}$ should be corrected with plasma expansion, inotropic drugs or an increase in $\mathrm{Hb}$. Like lactate, $\mathrm{S}_{\mathrm{cv}} \mathrm{O}_{2}$ has received much attention in the treatment of severe sepsis but has also been questioned. ${ }^{19}$ ${ }^{23}$ To our knowledge two studies have been published that used $\mathrm{S}_{\mathrm{cv}} \mathrm{O}_{2}$ as a primary target during abdominal surgery. ${ }^{24} 25$

\section{Oxygen Delivery}

Based on the landmark studies of Shoemaker in the 1980's, ${ }^{26}$ several studies have at the end of the past century explored the question whether an augmentation of oxygen delivery $\left(\mathrm{DO}_{2}\right)$ as measured by a pulmonary artery catheter (PAC) can be of benefit in surgical patients. $\mathrm{DO}_{2}$, which is the mathematical product of $\mathrm{CO}$ and $\mathrm{C}_{\mathrm{a}} \mathrm{O}_{2}$, was augmented by a combination of fluids, inotropes and blood transfusions and reported to have significant effects on morbidity and even mortality. ${ }^{27}$ However, the pulmonary catheter used in these studies is a highly invasive device which is not considered safe for use in the majority of routine surgical patients. Also, baseline mortality as reported in these older studies is not seen in modern practice.

\section{Stroke volume}

Since the millennium, several devices have been developed that claim to measure stroke volume (SV) without the associated risks of the PAC. The first studies in this field were done with oesophageal Doppler and LiDCO (see below). The most important component of these studies is the optimisation (or maximisation) of SV (SVO). This strategy centers on the Frank-Starling law of the heart, often depicted as a "Frank-Starling curve" (Fig 3 and 4). This law states that the force with which the heart contracts during systole, and thus the ensuing SV, is dependent on the stretch (length or tension) in cardiac muscle fibres before contraction, e.g. a greater force is generated when muscle fibres are stretched due to greater filling, up to a certain level. This principle is then conveniently translated as "when a fluid bolus results in a significant increase in SV (usually 10\%), 
the patient is fluid-responsive, has a position on the steep part of the Frank-Starling curve, and more fluid might be useful. If no significant response in SV ensues, the patient is a non-responder, positioned on the flat part of the Frank-Starling curve, and more fluid is not beneficial."

In clinical practice, SVO is usually applied using an algorithm, aiming at maintaining a near-maximal SV throughout the surgical procedure (Fig $5)$.

Figure 3 and 4. Frank-Starling curve of the heart, and its clinical application in optimisation of SV.
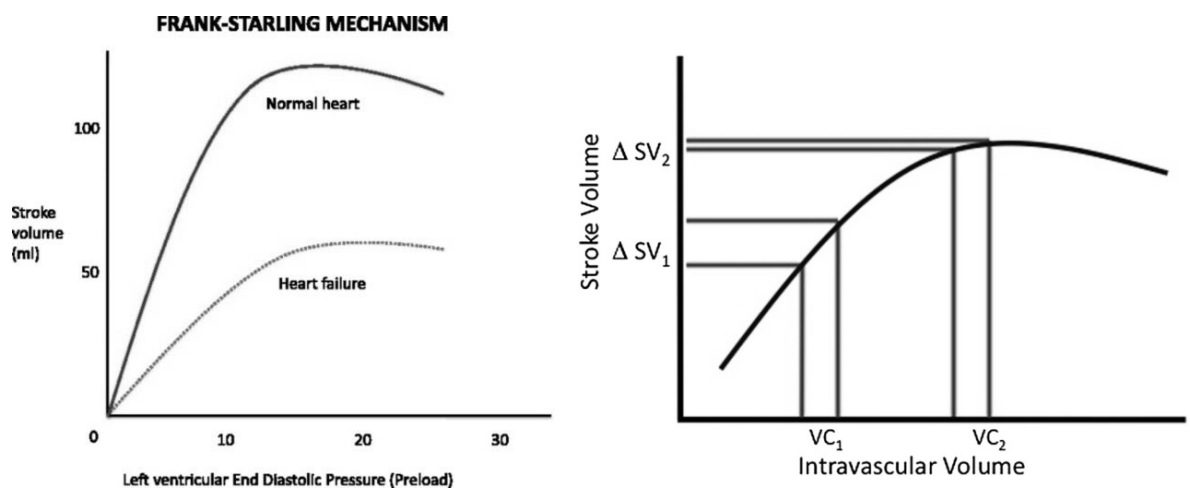

Figure 3 reproduced with permission from Neoreviews 2015;16. Copyright (C) 2015 by the American Academy of Pediatrics.

Figure 4 reprinted from Best Practice \& Research Clinical Anaesthesiology, 2009;23. Roche AM, Miller TE, Gan TJ. Goal-directed fluid management with trans-oesophageal Doppler, page 327-334. Copyright Elsevier Ltd. (2009). With permission from Elsevier.

\section{Dynamic parameters}

Dynamic parameters refer to a set of measurements of cyclic circulatory changes in for instance SV, related to changes in intrathoracic pressures during mechanical ventilation. A mechanical inflation is assumed to cause a decrease in venous return by increasing intrathoracic pressure. This cyclic decrease in venous return is then expected to cause a cyclic change in left ventricular preload, which will cause a cyclic change in SV, stroke volume variation (SVV), if the left heart is on the steep part of the FrankStarling curve. This in its turn would indicate that a fluid bolus would increase SV and that therefore the patient can be considered to be in a fluid responsive state. If cyclic changes of SV are absent or below a certain cutoff value, the patient is considered to be on the flat part of the FrankStarling curve and thus to be non-responsive to fluid (Fig 6). 
Figure 5. Example of SVO algorithm.

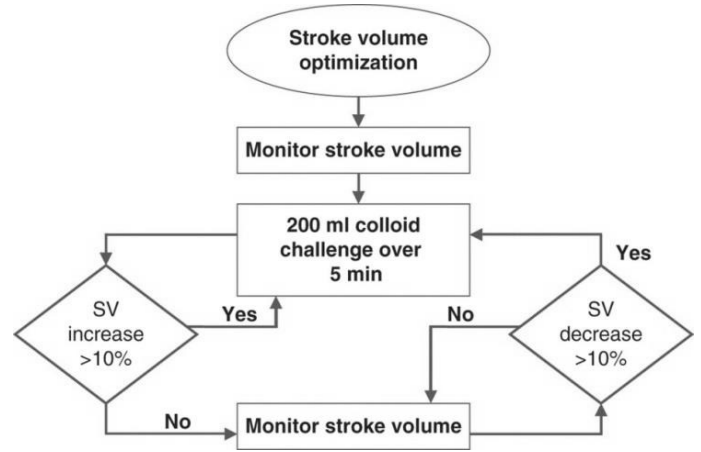

Reprinted from British Journal of Anaesthesia 2012;108. Challand C, Struthers R, Sneyd JR, Erasmus PD, Mellor N, Hosie KB, Minto G. Randomized controlled trial of intraoperative goal-directed fluid therapy in aerobically fit and unfit patients having major colorectal surgery, page 55. Copyright The Author(s) (2012). With permission from Elsevier.

Figure 6. Stroke volume variation induced by mechanical ventilation.

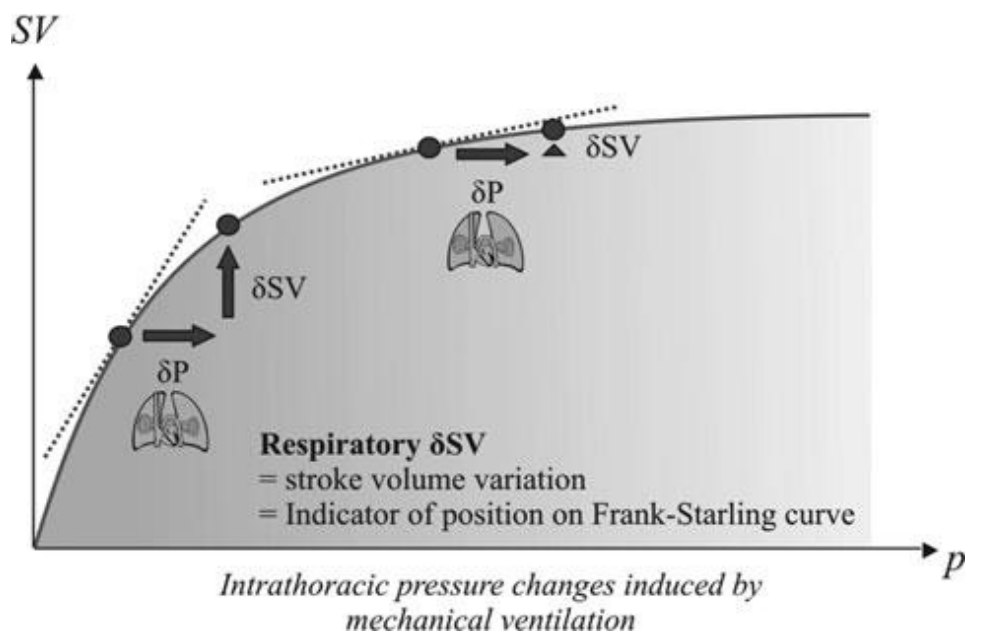

Reprinted with permission from Springer Nature Customer Service Centre GmbH: Springer Netherlands; Journal of Clinical Monitoring and Computing 2011;25:45-56. Pulse pressure variation: where are we today? Cannesson M, Aboy M, Hofer CK, Rehman M. (C) Springer Science+Business Media, LLC (2010). 
Since a variation in SV can be assumed to cause subsequent cyclic changes in blood pressure and peripheral pulsations, changes in these parameters, which can be measured completely non-invasively, are assumed to reflect SVV and thus whether a patient is in a fluid responsive state or not.

\section{Measurement devices}

As mentioned above, for most GDFT strategies, additional devices beyond standard anaesthesia monitoring equipment are needed. Early GDFT studies were performed with the pulmonary artery or Swan-Ganz catheter which functions through thermodilution. However due to its invasiveness, this device is no longer used in GDFT studies on abdominal surgical patients. An overview of alternative devices is given in Table 1.

Table 1. Overview of devices used in GDFT studies.

\begin{tabular}{|l|l|}
\hline Category & Device \\
\hline oesophageal Doppler & $\begin{array}{l}\text { - Cardioq-ODM, ODM+ (with pulse contour } \\
\text { analysis) } \\
\text { - Hemosonic Arrow (discontinued) }\end{array}$ \\
\hline cardiac Doppler & - USCOM \\
\hline cardiac ultrasound & - several \\
\hline $\begin{array}{l}\text { pulse contour analysis } \\
\text { - calibrated }\end{array}$ & $\begin{array}{l}\text { - PICCO (thermodilution) } \\
\text { - LiDCO(plus) (lithium dilution) } \\
\text { - CardioQ-ODM+ (oesophageal Doppler) }\end{array}$ \\
- uncalibrated & $\begin{array}{l}\text { - LiDCO (rapid) } \\
\text { - FloTrac (Vigileo (discontinued) / EV1000) }\end{array}$ \\
\hline non-invasive pressure / vascu- & $\begin{array}{l}\text { - Clearsight / Nexfin (+ photoplethysmo- } \\
\text { graphy) }\end{array}$ \\
lar unloading & - LiDCO CNAP \\
\hline bioimpedance / bioreactance & $\begin{array}{l}\text { - Cheetah NICOM / Starling SV } \\
\text { - ECOM (with arterial pulse contour analysis) }\end{array}$ \\
\hline Photoplethysmography & - PVI \\
\hline
\end{tabular}


The three GDFT devices used in this thesis: PVI, oesophageal Doppler and FloTrac, will be briefly described below.

\section{PVI}

Pleth variability index (PVI) is a method developed by Masimo. It is basically a refinement of existing photoplethysmographic technique used in commonly used pulse oximeters. Pulse oximeters are primarily used for measuring arterial oxygen saturation. This is measured by emitting light by a probe on e.g. a fingertip, measuring the amount of light absorbed by oxygenated and de-oxygenated blood, and deducting from it that part of light absorption which is non-pulsatile.

Figure 7. PVI probe and monitor

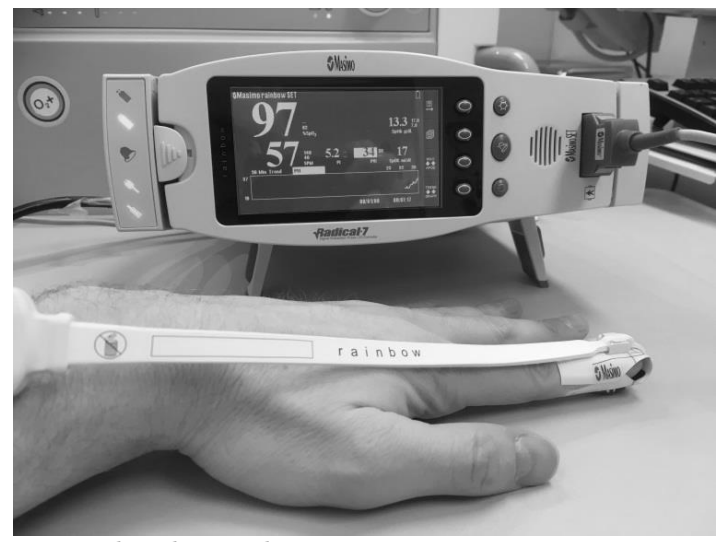

Image by the author

PVI calculates a perfusion index (PI) which is defined as the pulsatile light signal (AC) divided by the non-pulsatile signal (DC), and this is multiplied by 100 and expressed as a percentage, with a range of $0.02-20 \%$. Due to respiration (spontaneous or mechanical), SV varies cyclically, causing the pulsatile signal and thus PI to vary cyclically with respiration. The magnitude of this cyclic variation in PI is described by the pleth variability index (PVI) which is calculated as follows:

$$
\mathrm{PI}=\frac{\mathrm{AC}}{\mathrm{DC}} \times 100 \% \text {, and } \mathrm{PVI}=\frac{(\mathrm{PI}(\max )-\mathrm{PI}(\min )}{\mathrm{PI}(\max )} \times 100 \%
$$

Higher values of PVI are related to higher variations in SV during respiration and indicate a potential need for volume. Thus, PVI does not calculate SV but it is a completely non-invasive indicator of hypovolemia. 
The system also has an additional feature of measuring haemoglobin concentration non-invasively.

\section{Oesophageal Doppler}

The oesophageal Doppler (ODM), manufactured by Deltex Medical, consists of a single-use probe which is placed in the oesophagus and connected to a monitor. Using the Doppler principle, the device measures velocity

Figure 8. Oesophageal Doppler probe and monitor

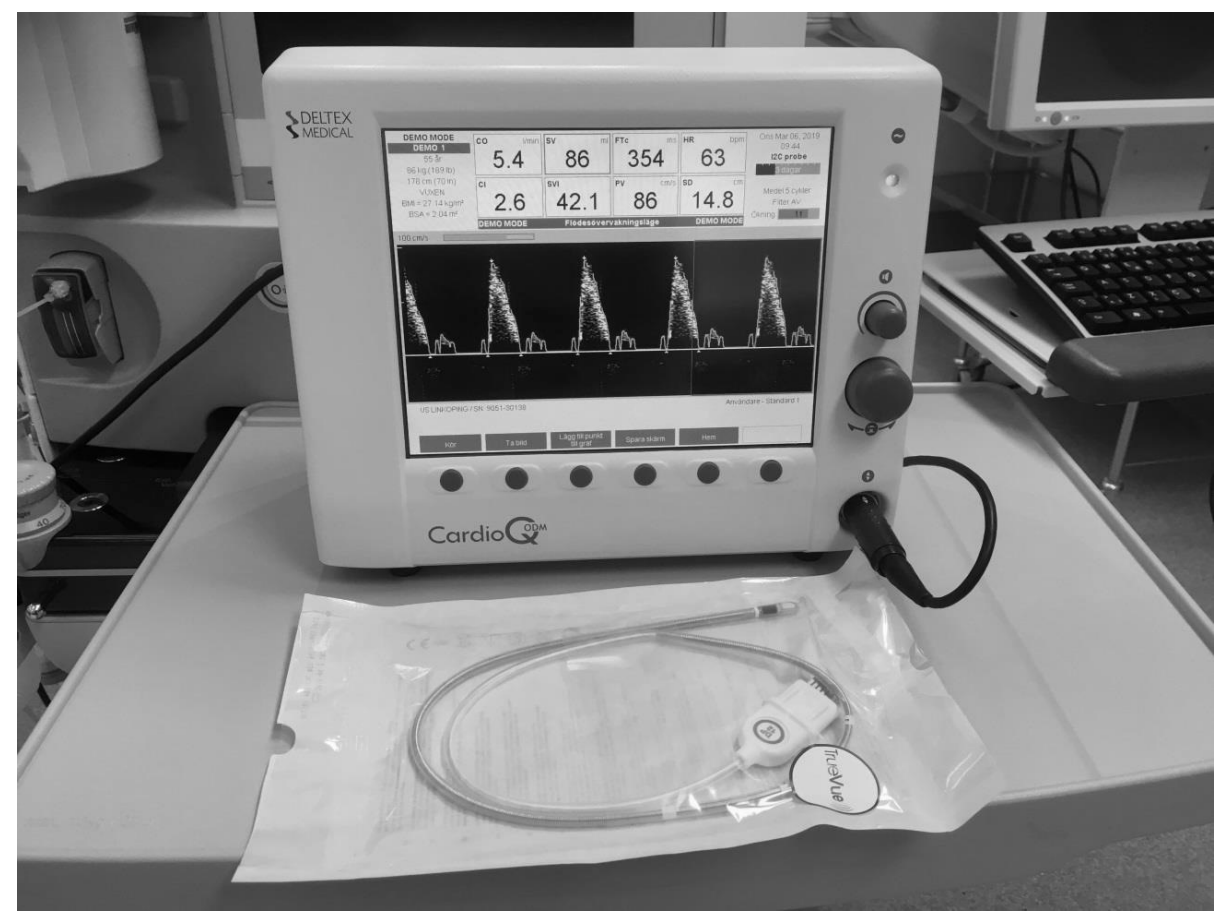

Image by the author

of blood flow in the descending aorta, where, in contrast to peripheral arteries, blood flow velocity is quite homogenous in a cross-section. Plotting velocity versus time results in the distance the blood travels during every heartbeat. Using biometric data such as length, weight and age, the monitor converses this distance to (stroke) volume by analysing a dataset of comparisons with simultaneous measurements done with a pulmonary artery catheter (PAC). In other words, this comparison yields a combined estimation of the aortic diameter at the site of measurement and a correction for the fact that blood leaving the aortic arch to the arms and head is not accounted for. Multiplying SV with heart rate gives the $\mathrm{CO}$. The device also reports other parameters such as corrected Flow Time and Peak Ve- 
locity which can be used to further analyse a patient's circulatory state. Modern versions of the device also offer the possibility of pulse contour analysis (see below).

\section{FloTrac}

FloTrac is a sensor produced by Edwards Lifesciences which is connected to a regular arterial (usually radial) line and connected to a monitor. The system analyses the arterial pressure waveform and calculates SV using complex and partially proprietary mathematical algorithms (pulse contour analysis) (http://ht.edwards.com/resourcegallery/products/ mininvasive/pdfs/flotrac_algorithm.pdf). FloTrac was one of the first commercially available less-invasive $\mathrm{CO}$ devices not needing calibration. In Study IV FloTrac was used together with the Vigileo-monitor. This monitor is now discontinued and instead FloTrac is used together with newer monitors.

Figure 9. FloTrac sensor with Vigileo monitor

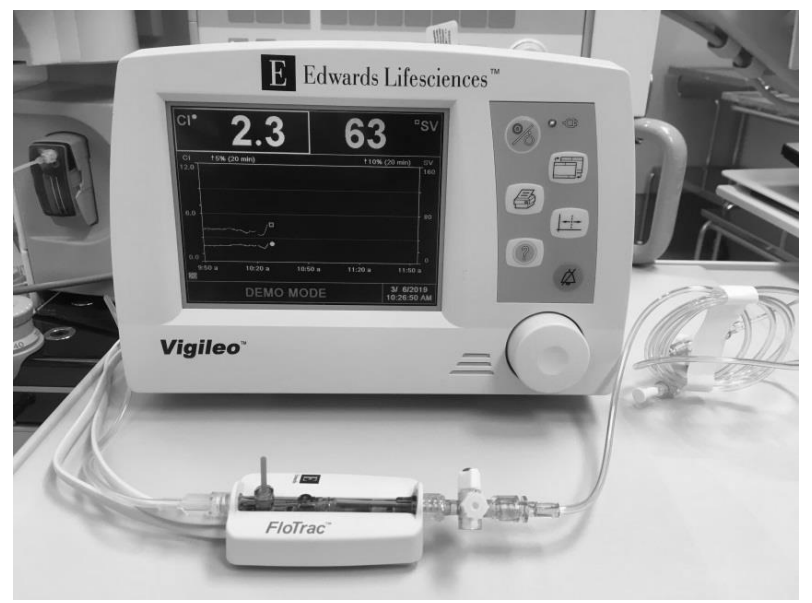

Image by the author

\section{Rationale for selection of devices}

The oesophageal Doppler was the primary device used in early studies on GDFT and most of these showed a positive effect on outcome. ${ }^{28}$ However the device is rather complicated since it requires training, sometimes frequent repositioning and thus access to the patient's face; it is also sensitive to disturbances, e.g. from diathermy, and requires a rather expensive single use probe. This is probably one of the reasons why GDFT is not universally applied. It is therefore of interest to evaluate whether more 
simple techniques for GDFT such as PVI are comparable to oesophageal Doppler, since this would facilitate the use of GDFT in more patients.

Also, in some surgical procedures such as oesophageal resection the oesophageal Doppler cannot be used. GDFT based on pulse contour analysis using FloTrac was reported to result in impressive improvements in outcome in mixed cohorts of surgical patients including oesophageal resection patients. ${ }^{29}$ Therefore, a similar if not more pronounced effect could be expected in a cohort consisting of only oesophageal resection patients, with a high risk of postoperative morbidity.

\section{Preoperative dehydration}

As mentioned before, it is not uncommon for patients to start surgery in a dehydrated state, caused by prolonged fasting, chronic medication such as diuretics, or increased fluid losses by e.g. bowel dysfunction and/or vomiting. Trying to keep patients as normally hydrated as possible before surgery has been one of the bedrocks of fast track surgical pathways such as ERAS (Enhanced Recovery After Surgery). This entails avoidance of bowel preparation, allowing intake of clear fluids until two hours before induction of anaesthesia and in many cases encouraging patients to drink some type of carbohydrate solution on the eve and the morning before surgery. $3^{\circ}$ The deleterious effects of preoperative dehydration have been confirmed by amongst others Cuthbertson et al. ${ }^{31}$ Also recently a large clinical trial was published which somewhat surprisingly showed that a restricted fluid strategy consistent with modern guidelines did not result in improved clinical outcome when compared with a, according to modern standards, quite liberal fluid strategy, and on the contrary seemed deleterious for renal function. ${ }^{22}$ However a large part of these patients appear to have been dehydrated before surgery due to prolonged fasting and a frequent use of bowel preparation.

Therefore it is of potential importance to take into account the hydration status of the individual patient before surgery. Even ERAS guided fluid management before surgery might still not be able to compensate for long-standing (subclinical) dehydration. Attempts have been made to quantify dehydration using objective methods. One of these is the Dehydration Index or Fluid Retention Index, described by Hahn et al.33 It is based on a urine sample which is assessed for colour, specific gravity, osmolality and concentration of creatinine, resulting in an index which correlates to the level of dehydration. 


\section{Volume kinetics}

Fluid infused intravenously usually leaves the intravascular compartment sooner or later, by equilibrating with other fluid compartments such as the interstitial or the intracellular spaces. Fluids equilibrate at different rates, depending on patient and fluid characteristics, and this can be studied by repeatedly measuring haemoglobin concentrations as well as diuresis after a fluid bolus. These haemoglobin values, together with diuresis, can then be used to describe the "volume kinetic" behaviour of an infused fluid. 34

During a fluid infusion the concentration of haemoglobin in the blood is expected to decrease by means of dilution, which reflects a volume expansion of a central compartment (the plasma). When infusion is stopped haemoglobin concentration will increase reflecting (continuing) clearance of fluid from the intravascular compartment. At the same time diuresis and constant losses such as insensible perspiration cause elimination of the fluid from the body. The difference between these two processes reflects the equilibration of the fluids with the peripheral compartment, which reflects the (for expansion accessible) interstitial and (though to a much lesser extent) intracellular space.

In mathematical terms, plasma expansion by an infusion $R_{0}$ can be described as $\frac{v c(t)-V c}{V c}$ where $v_{\mathrm{c}}(\mathrm{t})$ is the expanded plasma volume and $V_{\mathrm{c}}$ the plasma volume at baseline. If we suppose Hct is almost zero, Hgb is haemoglobin concentration at baseline and $\mathrm{Hgb}(\mathrm{t})$ the haemoglobin concentration after expansion then $\operatorname{Hgb} \times V_{\mathrm{c}}=\mathrm{Hgb}(\mathrm{t}) \times v_{\mathrm{c}}(\mathrm{t})$ and thus $\frac{v c(t)-V c}{V c}=$ $\frac{H g b-H g b(t)}{H g b(t)}$. Of course Hct is not almost zero, and since the change in haemoglobin concentration occurs in whole blood but the change in plasma volume occurs in the plasma we have to compensate by dividing by (1Hct), thus $\frac{v c(t)-V c}{V c}=\frac{\frac{H g b-H g b(t)}{H g b(t)}}{1-H c t}$.

Subsequently, plasma dilution is plotted versus time for all patients and an optimal average curve is fitted. Depending on the form of the curve, the measurements are best explained by a one or a twocompartment model (Fig 10). 
Figure 10. Plasma dilution by $25 \mathrm{ml} / \mathrm{kg}$ Ringer's acetate infused in 30 minutes, in 14 volunteers (A) and 14 patients during thyroid surgery (B). The optimal curve fit for $\mathrm{A}$ is a one compartment, and for $\mathrm{B}$ a two compartment model.
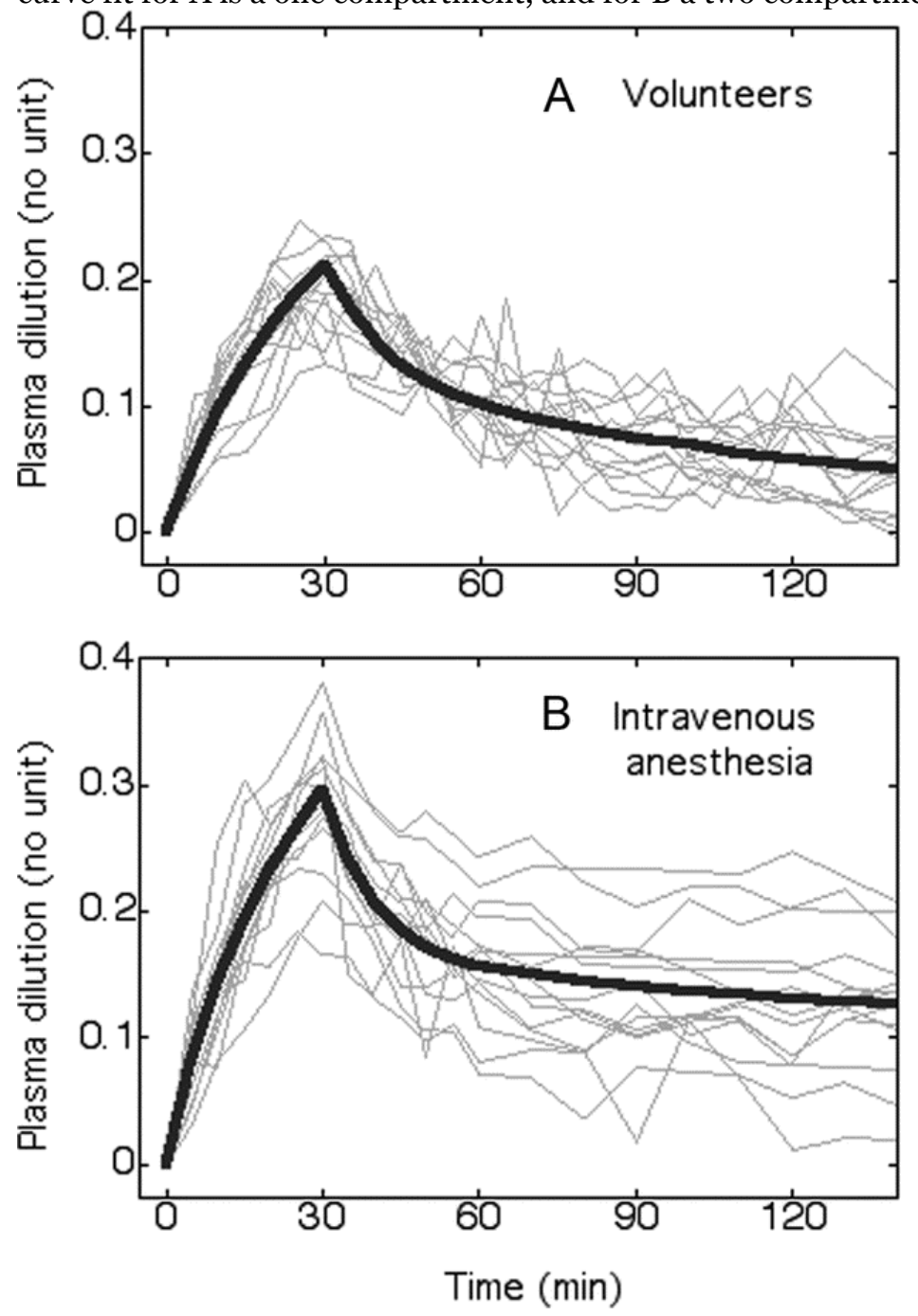

Reprinted from Hahn RG, Volume kinetics for infusion fluids. Anesthesiology 2010;113:470-81. American Society of Anesthesiology.

http://anesthesiology.pubs.asahq.org/article.aspx?articleid=1933333. With permission from Wolters Kluwer.

In a two-compartment model, besides the central compartment $V_{\mathrm{c}}$, there also exists a peripheral compartment $V_{\mathrm{p}}$ which is expanded to $v_{\mathrm{p}}$. The distribution between $V_{\mathrm{c}}$ and $V_{\mathrm{p}}$ is governed by the rate constant $k_{121}$. Fluids also leave the central compartment $V_{\mathrm{c}}$ through baseline diuresis and insensible perspiration at a constant rate (zero-order) $k_{0}$, assumed to 
be $0.4 \mathrm{ml} / \mathrm{min}$. Another part of diuresis is dependent on plasma dilution $\left(v_{\mathrm{c}}-V_{\mathrm{c}}\right)$ and a constant $k_{10}$.

In summary, the rate of change in the central compartment $\frac{d v c}{d \mathrm{t}}=R_{0}$ $k_{0}-k_{10}\left(v_{\mathrm{c}}-V_{\mathrm{c}}\right)-k_{121}\left[\left(v_{\mathrm{c}}-V_{\mathrm{c}}\right)-\left(v_{p}-V_{p}\right)\right]$. A schematic drawing of the model is shown in Fig. 11.

Figure 11. Schematic drawing of the kinetic model.

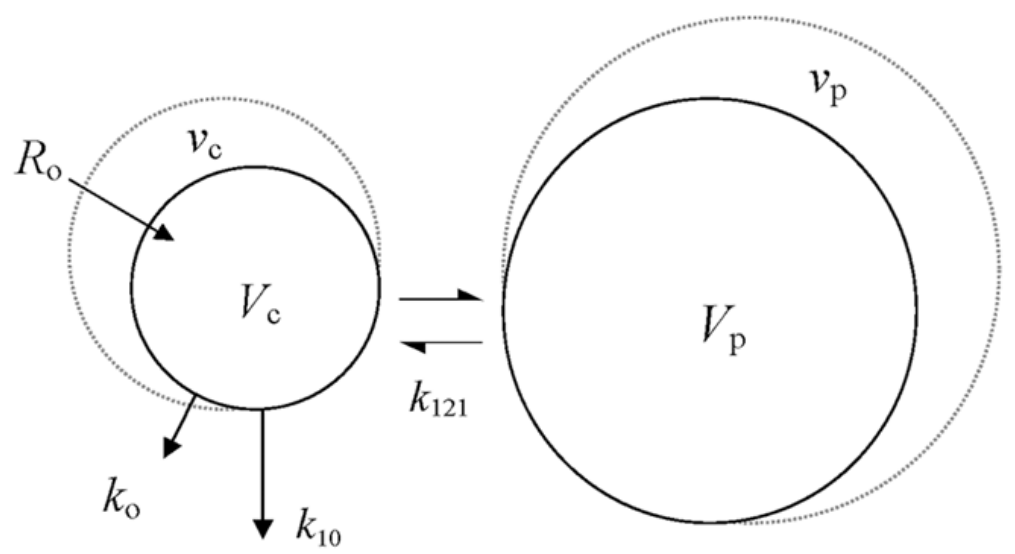

Reprinted from Hahn RG, Bahlmann H, Nilsson L. Dehydration and fluid volume kinetics before major open abdominal surgery. Acta Anaesthesiol Scand 2014;58:1258-1266. (C) 2014 The Acta Anaesthesiologica Scandinavica Foundation. With permission from John Wiley and Sons.

What you don't have, you don't need it now.

U2 


\section{AIMS}

The overall aims of this thesis are to compare an alternative, non-invasive and easy-to-use device for GDFT (PVI) with a more invasive and challenging reference method (oesophageal Doppler); to evaluate the incidence of preoperative dehydration and its effect on fluid handling by the body; and to confirm that GDFT in high risk surgical patients undergoing oesophageal resection leads to improved outcome. More specifically:

\section{Study I}

1. To examine the concordance between PVI and oesophageal Doppler when assessing the indication for and the effect of a fluid bolus during open abdominal surgery.

2. To assess the capacity of both methods to predict fluid responsiveness.

3. To assess whether these two methods result in different amounts of fluid being given for volume optimisation.

\section{Study II}

1. To assess the level of dehydration before elective major open abdominal surgery.

2. To assess whether dehydration as indicated by urine analysis is reflected in subsequent volume kinetics.

3. To assess whether volume kinetics can be reliably measured using non-invasive $\mathrm{Hb}$-measurements.

\section{Study III}

1. To assess whether patients having major open abdominal surgery, when randomised to GDFT based on PVI, have similar clinical outcome compared to patients randomised to GDFT using oesophageal Doppler, as quantified by the number of complications and length of stay.

\section{Study IV}

1. To study the effect on postoperative outcome of GDFT based on FloTrac in patients having elective oesophageal resection, as described by the incidence of complications, length of stay in the ICU and in hospital, and time until return of bowel function. 


\section{METHODS}

\section{Ethical considerations and registration}

Ethical permission was obtained from the Regional Ethical Review Board in Linköping on 30 March 2011 for Studies I-III (2011/101-31) and on 3 October 2011 for Study IV (2011/276-31). Study IV was also approved by the Swedish Medical Product Agency (2011-000254-39) on 11 October 2011. The studies were registered prospectively at clinicaltrials.gov, NCT 01458678 (Studies I-III) and NCT 01416077 (Study IV). Patients fulfilling the inclusion criteria described below received oral and written information on the study and when willing to participate consented orally and in writing.

\section{Patient selection and inclusion}

For Studies I-III adult patients scheduled for open general, urological or gynaecological surgery at University Hospital Linköping, with an expected duration of at least two hours, were screened for inclusion. Based on a sample size calculation (see below) 150 patients were randomised.

In the first half of this cohort (i.e. 75 patients), both PVI and oesophageal Doppler were measured in order to assess concordance between the methods, but only the allocated method was made accessible to the anaesthetist in charge. These results on concordance are presented in Study I.

Of the 75 patients in Study I, thirty, all of them first case surgeries, participated in the dehydration study described in Study II.

In Study III, where postoperative complications were analysed, all 150 patients were included.

In Study IV, a total of 64 patients scheduled for elective transthoracic oesophageal resection because of malignancy were included at University Hospital Linköping and at University Hospital Örebro.

\section{General patient management}

\section{Studies I \& III}

Patients were recruited from different departments (general surgery, urology, gynaecology) and their preoperative management followed local routine which could include an enhanced recovery program. Before in- 
duction of general anaesthesia an epidural catheter was sited when indicated and used during surgery. After induction of general anaesthesia patients were intubated and ventilated in volume control mode with a tidal volume of $7 \mathrm{ml} / \mathrm{kg}$ ideal body weight (IBW).

A maximum of $500 \mathrm{ml}$ of tetrastarch was allowed to be infused during siting of the epidural catheter and induction of anaesthesia. After induction a baseline infusion of $2 \mathrm{ml} / \mathrm{kg} / \mathrm{h}$ of $2.5 \%$ buffered dextrose was started. Bleeding was compensated 1:1 with colloids. Vasoconstrictors (norepinephrine or phenylephrine) and/or inotropes were uses at the discretion of the anaesthetist in charge of the patients.

\section{Study II}

Patients were instructed to fast from midnight, and arrived at the preanaesthetic bay around 6 am on the morning of surgery for the volumekinetic experiment described below. Afterwards they were managed as described above.

\section{Study IV}

All patients were fasted from midnight and in all patients an attempt was made to site an epidural catheter. After induction patients were intubated with a left-sided double-lumen tube. Patients were ventilated in volume control mode with a tidal volume of $7 \mathrm{ml} / \mathrm{kg}$ IBW during two-lung ventilation and $4 \mathrm{ml} / \mathrm{kg}$ IBW during one-lung ventilation. FiO2 was set to maintain a $\mathrm{SpO} 2$ of $>94 \%$ during two-lung ventilation and $>90 \%$ during onelung ventilation.

\section{Interventions and key measurements}

\section{Study I}

In all patients PVI was measured using a Radical 7 Pulse CO-oximeter. Oesophageal Doppler measurements were done using a single-use DP12 probe and a CardioQ apparatus. All patients received both devices but only the allocated device was visible to the anaesthetist in charge of the patient.

In the PVI group, a fluid bolus of $3 \mathrm{ml} / \mathrm{kg}$ tetrastarch was given when PVI $\geq 10 \%$. If PVI decreased below $10 \%$ after 5 minutes this was considered fluid responsiveness and no more fluid was given. If PVI decreased but was still $\geq 10 \%$ this was also considered as fluid responsiveness and another fluid bolus was given. Additional fluid boluses were given until PVI fell below $10 \%$ or did not decrease at all; the latter situation was considered non-responsiveness. A series of fluid boluses was called an opti- 
misation round and additional rounds were initiated when PVI increased to $10 \%$ or more. For the sake of comparison with oesophageal Doppler, a first fluid bolus was given after induction to all patients, irrespective of PVI value.

In the oesophageal Doppler group, SV was measured after induction and a fluid bolus given. If SV after 5 minutes had increased $\geq 10 \%$ this was considered fluid responsiveness and additional boluses were given in the same manner until the SV no longer increased with $10 \%$ or more. In parallel with the PVI group, such a series of fluid boluses was called an optimisation round and additional optimisation rounds were initiated whenever SV decreased $\geq 10 \%$.

Before and after each fluid bolus, PVI and oesophageal Doppler data were recorded by a member of the research team not involved in patient care and analysed at a later time. We compared the concordance for both methods for categorically assessing whether a fluid bolus was indicated

Table 2. Criteria used retrospectively to determine, for both PVI and Doppler, whether a fluid bolus infusion was indicated according to the algorithm, and/or resulted in fluid responsiveness. * A fluid bolus was given to all patients in both groups according to the protocol. Since no previous SV values were available, it cannot be determined whether this first fluid bolus was indicated or not according to Doppler.

\begin{tabular}{|c|c|c|c|c|}
\hline & \multicolumn{2}{|c|}{$\begin{array}{l}\text { Fluid bolus was indicated } \\
\text { according to the algorithm }\end{array}$} & \multicolumn{2}{|c|}{$\begin{array}{l}\text { Fluid responsiveness } \\
\text { according to the algorithm }\end{array}$} \\
\hline & PVI & Doppler & PVI & Doppler \\
\hline $\begin{array}{l}\text { Very first fluid bo- } \\
\text { lus in the first opti- } \\
\text { misation round }\end{array}$ & $\mathrm{PVI} \geq 10 \%$ & Not analysed ${ }^{*}$ & $\begin{array}{l}\text { Initial PVI value } \\
\geq 10 \% \text { and } \\
\text { reduction after } \\
\text { fluid bolus }\end{array}$ & $\begin{array}{l}\text { Increase in SV } \\
\text { of } \geq 10 \%\end{array}$ \\
\hline $\begin{array}{l}\text { First fluid bolus in } \\
\text { an optimisation } \\
\text { round }\end{array}$ & $\mathrm{PVI} \geq 10 \%$ & $\begin{array}{l}\text { Reduction in } \\
\text { SV of } \geq 10 \%\end{array}$ & $\begin{array}{l}\text { Initial PVI value } \\
\geq 10 \% \text { and re- } \\
\text { duction after } \\
\text { fluid bolus }\end{array}$ & $\begin{array}{l}\text { Increase in SV } \\
\text { of } \geq 10 \%\end{array}$ \\
\hline $\begin{array}{l}\text { Subsequent fluid } \\
\text { boluses in an opti- } \\
\text { misation round }\end{array}$ & $\begin{array}{l}\mathrm{PVI} \geq 10 \% \text { and } \\
\text { a decrease } \\
\text { from previous } \\
\text { value }\end{array}$ & $\begin{array}{l}\text { Increase in } \\
\text { SV by } \geq 10 \% \\
\text { by previous } \\
\text { fluid bolus }\end{array}$ & $\begin{array}{l}\text { Initial PVI value } \\
\geq 10 \% \text { and re- } \\
\text { duction after } \\
\text { fluid bolus }\end{array}$ & $\begin{array}{l}\text { Increase in SV } \\
\text { of } \geq 10 \%\end{array}$ \\
\hline
\end{tabular}


(yes or no) and whether a fluid bolus resulted in fluid responsiveness as defined above (yes or no). The criteria for each method are shown in Table 2. We also calculated the positive and negative predictive value for both methods for predicting an increase in $\mathrm{SV} \geq 10 \%$.

\section{Study II}

\section{Urinary analysis}

Patients voided right before the start of the experiment. A urine sample was assessed for colour, specific gravity, creatinine and osmolality.

Each parameter resulted in a score, and the mean of these four scores was called the dehydration index. DI values $>3.5$ were regarded to present dehydration. Patients participating only in Studies I and/or III voided shortly before transport to the anaesthetic bay and a urine sample was analysed as described above.

\section{Volume kinetics}

Patients received two iv cannulas, one for fluid administration and one for blood sampling. An infusion of $5 \mathrm{ml} / \mathrm{kg}$ Ringer's acetate was then given over $15 \mathrm{~min}$. Blood samples were taken at 5 to 10 minutes intervals and analysed for $\mathrm{Hb}$. $\mathrm{Hb}$ was also measured non-invasively via the Radical-7 Pulse CO-Oximeter. After the last sample, 70 minutes after the start of the infusion with Ringer's acetate, patients voided again and the volume was measured.

\section{Study III}

Complications during the first 30 days after surgery were retrospectively documented by two blinded observers using a pre-specified list (See Appendix, Table 1)

\section{Study IV}

Patients randomised to the intervention group received a baseline infusion of $2.5 \mathrm{ml} / \mathrm{kg} / \mathrm{h}$ buffered dextrose. A maximum of $1000 \mathrm{ml}$ of Ringer's acetate could be infused if preoperative dehydration was suspected.

After induction, a FloTrac pressure transducer was connected to the radial artery line and SV measured. Stroke volume optimisation (SVO) was performed using fluid boluses of $3 \mathrm{ml} / \mathrm{kg}$ tetrastarch given during 5 minutes. If SV increased $>10 \%$ another bolus was given. This was repeated until SV did not increase $>10 \%$. SV was continuously monitored and when decreasing $>10 \%$ a new fluid bolus round as described above was initiated. 
If Cardiac Index (CI) $<2.5 \mathrm{l} / \mathrm{min} / \mathrm{m}^{2}$ despite SVO, an infusion of dobutamine was started and increased until CI increased above 2.5 $\mathrm{ml} / \mathrm{kg} / \mathrm{m}^{2}$ or side-effects occurred.

As the third goal, if Mean Arterial Pressure (MAP) was $<65 \mathrm{mmHg}$, an infusion with norepinephrine or phenylephrine was started.

Patients randomised to the control group received fluids and vasoactive drugs at the discretion of the responsible anaesthetist. In both groups a maximum of $30 \mathrm{ml} / \mathrm{kg}$ tetrastarch was allowed, and bleeding was compensated for $1: 1$ with a suitable colloid.

Postoperative complications were assessed at 5 and 30 days postoperatively by a research nurse using a predefined complication scoring list (see Appendix, Table 2). In addition, complications were assessed retrospectively by one surgeon and two anaesthetists blinded to allocation.

\section{Statistics}

Demographic, perioperative and biochemical data were compared using Student's $t$-test, Mann-Whitney $U$-test, Fisher's Exact test or chi-square test as appropriate.

In Study I Cohen's kappa was calculated for the concordance between PVI and oesophageal Doppler regarding the indication and effect of a fluid bolus. Usually values between 0 and 0.2 indicate slight, between 0.2 and 0.4 fair, between 0.4 and 0.6 moderate, between 0.6 and 0.8 substantial and between 0.8 and 1 almost perfect concordance. 35 Also, a grey zone was calculated, defined as the range of cut-off values for PVI and change in SV resulting in a sensitivity and specificity below 90\%, however without the bootstrapping described by Cannesson et al. ${ }^{6}$

\section{Sample size}

For Studies I-III, a sample size calculation was performed that would be sufficient for the endpoint postoperative complications (reported in Study III). Based on data from five previous studies on GDFT during abdominal surgery, it was calculated that 66 patients would need to be included in each group to demonstrate an absolute difference in postoperative complications of $10 \%$. Taking into account dropouts it was decided to include 150 patients.

Of these 150 patients, it was estimated that 75 patients (the first half of the total cohort) would be needed to quantify the concordance between both methods (Study I). And of these 75 patients, it was estimated that 30 would be needed for the dehydration experiment (Study II). 
For Study IV, a sample size calculation was performed based on two previous reports using FloTrac in abdominal surgery showing highly significant results, i.e. a reduction of $50 \%$ or more in the incidence of postoperative complications. ${ }^{29} 37$ Since we expected that GDFT would have at least the same if not even a more pronounced effect in our population of high-risk surgical patients, we calculated that 29 patients would need to be included in each arm. To compensate for dropouts it was decided to include 64 patients in the study.

Vem har gallringsbehov? Den frågan kan man ju ställa sig. Oftast blir svaret inte, det är skogsinspektör'n som har gallringsbehov. Skogen och skogsägaren har inget gallringsbehov.

Tvillingarna Eriksson

(Who is in need of thinning? That's a question to be asked. Often the answer is no, it's the forest inspector who needs thinning. The forest or the forest owner do not need thinning.

The Eriksson twins) 


\section{RESULTS}

\section{Studies I-III}

Patients were recruited between 14 November 2011 and 8 December 2014. Patient and surgical characteristics were comparable between the groups. Median duration of surgery was around three hours with some procedures lasting more than 12 hours. In total four patients were excluded, leaving 74 patients in the PVI and 72 patients in the oesophageal Doppler group available for analysis.

There were no significant differences in the amount of fluid used for the optimisations between the groups, nor in other fluid parameters or catecholamine treatment both in Study I (the first half of the cohort) as well as Study III (the whole cohort) (Table 3), with the exception of an increased use of phenylephrine in the PVI group.

Table 3. Intraoperative fluid and catecholamine data. Significant differences in bold.

\begin{tabular}{|c|c|c|c|}
\hline & $\begin{array}{l}\text { PVI } \\
(n=74)\end{array}$ & $\begin{array}{l}\text { Doppler } \\
(\mathrm{n}=72)\end{array}$ & $P$ \\
\hline Crystalloid fluid, mean (SD), ml & $1360(749)$ & $1240(662)$ & 0.31 \\
\hline Total colloid fluid, mean (SD), ml & $1464(1000)$ & $1412(1259)$ & 0.92 \\
\hline Colloid during induction, mean (SD), ml & $173(145)$ & $154(137)$ & 0.40 \\
\hline $\begin{array}{l}\text { Colloid used during optimisations, mean (SD), } \\
\mathrm{ml}\end{array}$ & $675(434)$ & $665(462)$ & 0.89 \\
\hline Synthetic colloid fluid, mean (SD), ml & $1159(507)$ & $1141(532)$ & 0.84 \\
\hline Albumin $5 \%, \mathrm{n}$ (range, ml) & $14(120-1250)$ & $8(170-500)$ & 0.25 \\
\hline Albumin $20 \%, \mathrm{n}$ (range, ml) & $8(100-200)$ & $6(45-100)$ & 0.78 \\
\hline Red blood cells, n (range, ml) & $10(280-1389)$ & $8(265-2310)$ & 0.80 \\
\hline Plasma, n (range, ml) & $6(776-2734)$ & $5(265-3300)$ & 1.00 \\
\hline Thrombocytes, n (range, ml) & 0 & $2(230-250)$ & 0.24 \\
\hline Phenylephrine, $\mathrm{n}$ (range, $\mu \mathrm{g}$ ) & $51(360-3928)$ & $37(240-6640)$ & 0.04 \\
\hline Norepinephrine, $\mathrm{n}$ (range, $\mu \mathrm{g})$ & $29(52-2180)$ & $30(11-2726)$ & 0.76 \\
\hline Dobutamine, n (range, mg) & $20(2-110)$ & $20(1-97)$ & 0.92 \\
\hline Blood loss, median [IQR], ml & $250[100-600]$ & 225 [88-575] & 0.41 \\
\hline Urine, median [IQR], ml & $300[174-500]$ & 225 [125-435] & 0.22 \\
\hline
\end{tabular}




\section{Concordance between and performance of PVI and oesophage- al Doppler}

In $31 \%$ of the situations where a fluid bolus was indicated according to Doppler, PVI agreed. In $72 \%$ of the situations where there was no indication for fluid according to oesophageal Doppler, PVI agreed (Table 4-A). Cohen's kappa was o.o3 i.e. slight concordance.

Regarding determining whether a fluid bolus resulted in a positive response PVI agreed with oesophageal Doppler in 50 of 99 optimisations deemed positive by oesophageal Doppler (50\%), and in 88 out of 143 optimisations deemed not positive according to oesophageal Doppler (62\%) (Table 4-B). Cohen's kappa was o.11 i.e. slight concordance.

Since no formal sample size calculation had been made, a post-hoc power analysis was performed which showed that the size of the study resulted in a power of $>0.99$ to detect a kappa of 0.4 at the 0.001 significance level for both comparisons.

In $48 \%$ of the cases where a fluid bolus was indicated according to the PVI algorithm, SV increased by $\geq 10 \%$. For oesophageal Doppler, $45 \%$ of indicated fluid boluses resulted in an increase in SV $\geq 10 \%$ (Table 4 -C). The first fluid bolus in a new optimisation round, initiated after a decrease in SV by $\geq 10 \%$, increased SV by $\geq 10 \%$ in $58 \%$. Subsequent fluid boluses increased $\mathrm{SV} \geq 10 \%$ only in $19 \%$.

Some fluid boluses which were not indicated according to oesophageal Doppler did result in a significant increase in SV (23 of 72 fluid boluses i.e. 32\%), and "illogical" responses occurred, e.g. a first fluid bolus without a significant effect on SV followed by a second fluid bolus causing a significant increase.

In Fig. 12 individual PVI values before a fluid bolus are plotted against the subsequent change in SV. For PVI the grey zone, reflecting values where fluid responsiveness cannot be reliably predicted, was between 6 and $16 \%$. Seventy-five percent of measurements were within this zone. For the Doppler algorithm, the grey zone in pre-bolus change in SV was between -37 to $+23 \%$ : $89 \%$ of measurements were within this zone.

Using ROC curves, the optimal cut-off PVI value for predicting an increase in SV by $>10 \%$ was $10.5 \%$. This cut-off value had a sensitivity of 0.53 and a specificity of 0.62 . 
Table 4A-C.

A. Agreement between PVI and Doppler regarding whether a fluid bolus was indicated, according to the respective algorithm. B. Agreement between PVI and Doppler regarding whether a fluid bolus resulted in fluid responsiveness. C. Positive and negative predictive values for an increase in SV $\geq 10 \%$ after a fluid bolus for both PVI and Doppler. + Percentage of true positives for indicated fluid boluses or percentage of true negatives for not indicated fluid boluses.

Data are combined for all 74 patients in both groups. Values denote number of optimisations or percentage.

\begin{tabular}{|c|c|c|c|}
\hline \multicolumn{2}{|l|}{$\bar{A}$} & $\begin{array}{l}\text { Indicated according } \\
\text { to Doppler }\end{array}$ & \multirow{2}{*}{$\begin{array}{l}\text { Not indicated ac- } \\
\text { cording to Doppler } \\
56\end{array}$} \\
\hline Indicated according to & $\overline{P V I}$ & 53 & \\
\hline Not indicated according & $g$ to $\mathrm{PVI}$ & 117 & 144 \\
\hline $\bar{B}$ & & $\begin{array}{l}\text { Fluid responder ac- } \\
\text { cording to Doppler }\end{array}$ & $\begin{array}{l}\text { Fluid non-responder } \\
\text { according to Dop- } \\
\text { pler }\end{array}$ \\
\hline Fluid responder accord & ing to PVI & 50 & 55 \\
\hline $\begin{array}{l}\text { Fluid non-responder a } \\
\text { PVI }\end{array}$ & ccording to & 49 & 88 \\
\hline $\bar{C}$ & $\begin{array}{l}\text { SV increase } \\
\geq 10 \%\end{array}$ & $\begin{array}{l}\text { SV increase } \\
<10 \%\end{array}$ & $\begin{array}{l}\text { Predictive } \\
\text { valuet }\end{array}$ \\
\hline Indicated by PVI & 56 & 61 & $48 \%$ \\
\hline Not indicated by PVI & 44 & 83 & $65 \%$ \\
\hline Indicated by Doppler & 48 & 59 & $45 \%$ \\
\hline $\begin{array}{l}\text { Not indicated by Dop- } \\
\text { pler }\end{array}$ & 23 & 49 & $68 \%$ \\
\hline
\end{tabular}


Fig 12. Values of PVI in both groups related to subsequent changes in SV. The correlation was $0.09, P=0.15$.

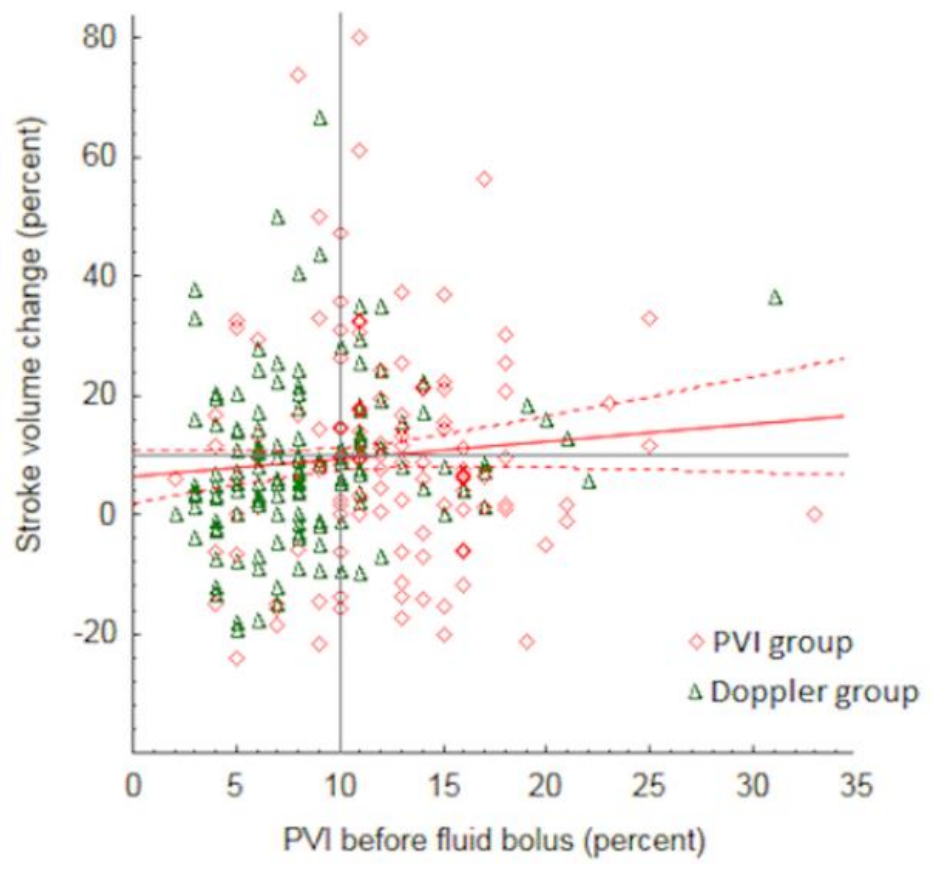

The distribution of perfusion index (PI) values in Study I is shown in Fig 13 . Out of 542 recordings, $323(60 \%)$ were above 4 (See discussion page 56).

Figure 13. Distribution of perfusion index values in Study I.

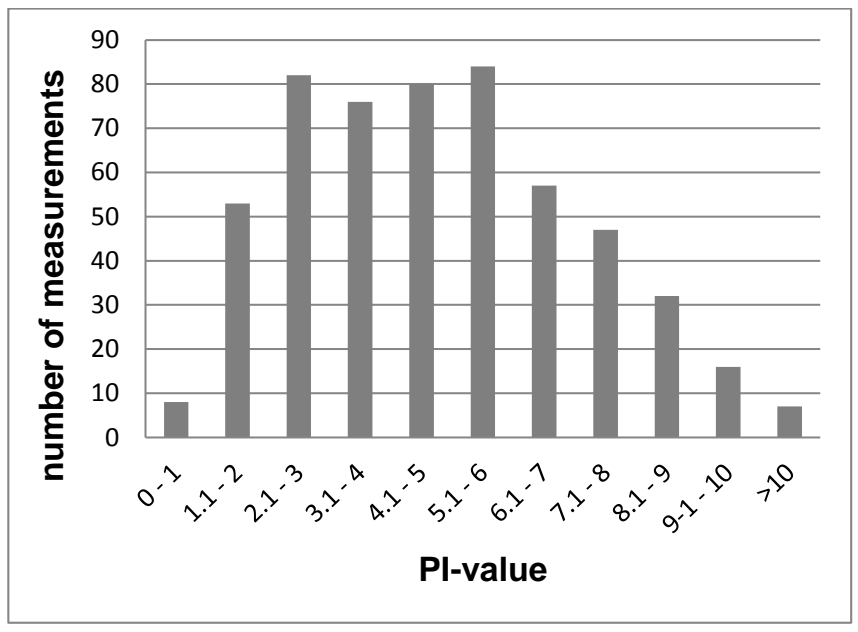




\section{Dehydration and fluid kinetics}

\section{Dehydration}

The median DI was 2.8 [IQR 2.5-3.7]. Eleven out of 30 patients had a DI of $>3.5$ and were considered dehydrated. In one dehydrated patient invasive $\mathrm{Hb}$ data were not reported leaving 29 patients (of which 10 dehydrated) available for analysis of fluid kinetics.

\section{Fluid kinetics}

A computer simulation of the volume changes in the central and peripheral fluid compartments and diuresis in both groups is shown in Fig 14. Distribution to the peripheral compartment was rapid in the euhydrated group but slow in the dehydrated group. For the other parameters differences were not significant. Numerical values for the kinetic parameters are shown in Table 5 .

Figure 14. Computer simulation of the volume changes in a central fluid compartment $V$ c (red), a peripheral fluid compartment, $V p$ (blue), and the excreted urine (magenta) over time in euhydrated or dehydrated patients.

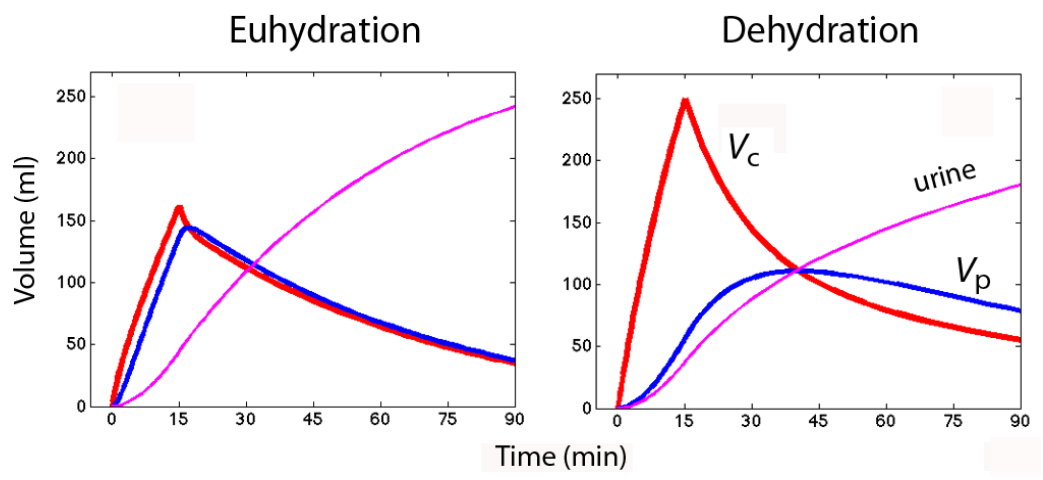

Table 5. Fluid kinetic parameters in the euhydrated and dehydrated groups. Data are median [interquartile range].

\begin{tabular}{lccr}
\hline & $\begin{array}{c}\text { Euhydration } \\
(\mathrm{N}=19)\end{array}$ & $\begin{array}{c}\text { Dehydration } \\
(\mathrm{N}=10)\end{array}$ & $\boldsymbol{P}$ \\
\hline$V_{\mathrm{c}} / \mathrm{BW}(\mathrm{ml} / \mathrm{kg})$ & $19[12-25]$ & $30[23-44]$ & 0.06 \\
$k_{121}\left(10^{-3} \mathrm{~min}^{-1}\right)$ & $363[148-570]$ & $32[18-57]$ & $<0.01$ \\
$k_{10}\left(10^{-3} \mathrm{~min}^{-1}\right)$ & $33[21-142]$ & $18[11-32]$ & 0.36
\end{tabular}




\section{Fluid kinetics using non-invasive $\mathrm{Hb}$}

Measurement of non-invasive $\mathrm{Hb}$ failed to produce usable dilution curves in eleven patients and in one patient invasive $\mathrm{Hb}$ measurements were not delivered. For the remaining 18 patients median values and IQR for the kinetic parameters were similar, however on an individual base there were no significant correlations between the invasively and non-invasively derived values for $V c$, nor between the two values for $k_{121}$ (Table 6). Values for $k_{10}$ were correlated though $\left(r^{2}=0.38\right)$. Curve fitting using noninvasive $\mathrm{Hb}$ was associated with significantly larger mean square errors compared to using invasive $\mathrm{Hb}$.

Table 6. Fluid kinetic parameters for both invasive and non-invasive $\mathrm{Hb} .{ }^{*} \mathrm{Be}-$ tween invasive and non-invasive $\mathrm{Hb}$ in experiments where both invasive and non-invasive $\mathrm{Hb}$ could be analysed. ${ }^{* *} P<0.01$

\begin{tabular}{lccc}
\hline & $\begin{array}{c}\text { All invasive Hb } \\
(\mathrm{N}=29)\end{array}$ & $\begin{array}{c}\text { Invasive Hb } \\
\text { matched }^{*}(\mathrm{~N}=18)\end{array}$ & $\begin{array}{c}\text { Non-invasive Hb } \\
\text { matched }^{\star}(\mathrm{N}=18)\end{array}$ \\
\hline$V_{\mathrm{c}} / \mathrm{BW}(\mathrm{ml} / \mathrm{kg})$ & $22[16-31]$ & $24[15-35]$ & $23[14-35]$ \\
$k_{121}\left(10^{-3} \mathrm{~min}^{-1}\right)$ & $236[34-422]$ & $193[30-569]$ & $235[210-1424]$ \\
$k_{10}\left(10^{-3} \mathrm{~min}^{-1}\right)$ & $30[11-97]$ & $33[20-165]$ & $34[9-97]$ \\
Mean square error & $2.6[1.1-4.2]$ & $2.6[1.3-3.4]$ & $5.4[2.8-6.5]^{\star *}$
\end{tabular}

\section{Dehydration and volume optimisation.}

In the whole cohort of Studies I-III, no correlation was found between preoperative dehydration as quantified by the dehydration index, and presumed preoperative hypovolemia as quantified by the volume of colloid needed during induction and the first optimisation round (Fig 15).

Figure 15. Correlation between preoperative dehydration and amount of colloid until after first optimisation round.

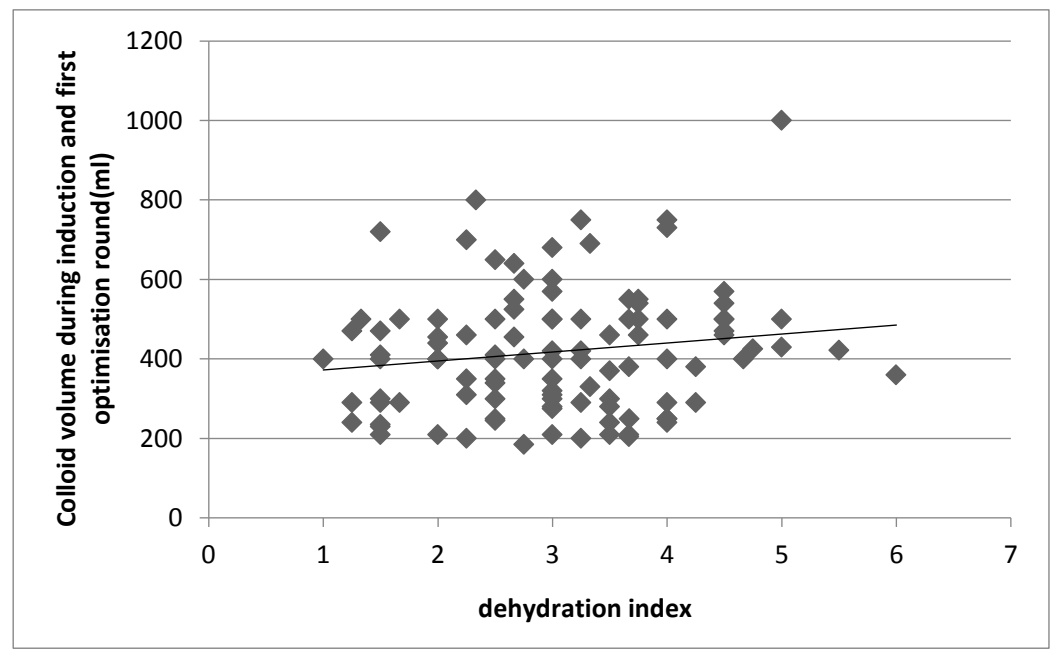




\section{Clinical outcome}

As mentioned above follow-up was complete in 146 patients. There was no mortality during the 30-day observation period. There were $64 \mathrm{com}$ plications in the PVI group ( $\mathrm{n}=74)$ compared to 70 in the oesophageal Doppler group $(\mathrm{n}=72)(P=0.93)$ (Table 7$)$. Thirty-eight $(51 \%)$ of patients in the PVI group had at least one complication compared to 35 (49\%) in the oesophageal Doppler group $(P=0.74)$. Length of hospital stay was 8 [5-13] (median [IQR]) in the PVI group and 8 [5-14.5] in the oesophageal Doppler group.

Table 7. Postoperative complications within 30 days after surgery.

\begin{tabular}{|c|c|c|c|}
\hline & & $\begin{array}{l}\text { PVI } \\
(n=74)\end{array}$ & $\begin{array}{l}\text { Doppler } \\
(\mathrm{n}=72)\end{array}$ \\
\hline \multirow[t]{17}{*}{ MAJOR } & Anastomotic insufficiency & 3 & 1 \\
\hline & Lymphatic leakage & 0 & 0 \\
\hline & Bleeding & 0 & 1 \\
\hline & Sepsis & 0 & 1 \\
\hline & Wound dehiscence & 0 & 5 \\
\hline & Intestinal obstruction & 0 & 1 \\
\hline & Stroke & 0 & 0 \\
\hline & Pulmonary embolism & 0 & 0 \\
\hline & Deep vein thrombosis & 1 & 1 \\
\hline & $\begin{array}{l}\text { Pulmonary oedema / respiratory insufficiency } \\
\text { / pneumonia }\end{array}$ & 1 & 2 \\
\hline & Pleural effusion & 0 & 5 \\
\hline & Myocardial infarction & 1 & 0 \\
\hline & Arrhythmia & 1 & 2 \\
\hline & Cardiac arrest & 0 & 0 \\
\hline & Renal dysfunction & 13 & 10 \\
\hline & Liver dysfunction & 0 & 0 \\
\hline & TOTAL & 20 & 29 \\
\hline \multirow[t]{5}{*}{ MINOR } & Superficial wound infection or dehiscence & 6 & 4 \\
\hline & Infection & 10 & 11 \\
\hline & Paralytic ileus & 1 & 0 \\
\hline & Upper GI bleeding & 0 & 1 \\
\hline & Pulmonary congestion & 5 & 0 \\
\hline
\end{tabular}




\begin{tabular}{lrr}
\hline Angina pectoris & 1 & 1 \\
Hypotension & 2 & 6 \\
Delirium & 1 & 1 \\
Coagulopathy & 4 & 3 \\
Severe postoperative nausea and vomiting & 8 & 9 \\
Urinary retention & 6 & 5 \\
TOTAL & 44 & 41 \\
& & \\
Total number of complications & $\mathbf{6 4}$ & $\mathbf{7 0} \quad(\boldsymbol{P}=\mathbf{0 . 9 3})$ \\
Number (\%) of patients with complications & $\mathbf{3 8}(\mathbf{5 1})$ & $\mathbf{3 5}(\mathbf{4 9}) \quad(P=\mathbf{0 . 7 4})$ \\
Mean number of complications in patients with compli- & $\mathbf{1 . 7}$ & $\mathbf{2 . 0} \quad(P=\mathbf{0 . 2 8})$ \\
cations & &
\end{tabular}

\section{Study IV}

Patients were consecutively included between 31 October 2011 and 8 September 2015. In five patients surgery was aborted or cancelled due to metastatic disease; for the remaining 59 follow-up was complete.

The groups were comparable with the exception of higher O-POSSUM scores (a surgical risk score adapted to oesophageal resection ${ }^{38}$ ) in the control group $(P=0.04)$.

Patients in the intervention groups received a larger amount of colloids (Table 8), however the difference in total intra-operative fluid balance did not reach significance, nor did perioperative fluid balance and body weight changes. Only one third of fluid boluses resulted in a significant increase in SV. Dobutamine was used in 27 out of 30 intervention patients in contrast to nine out of 29 control patients $(P<0.01)$. 
Table 8. Intraoperative fluids and catecholamines. Data are presented as median and interquartile range, mean and standard deviation or number of patients. Significant results in bold.

\begin{tabular}{lccr}
\hline & Intervention $(\mathrm{n}=30)$ & Control $(\mathrm{n}=29)$ & $\boldsymbol{P}$ \\
\hline Blood loss, ml & $475[250-800]$ & $400[250-650]$ & 0.59 \\
Urine, ml & $528[415-800]$ & $505[445-780]$ & 0.62 \\
Total colloid fluid, ml & $2190(875)$ & $1596(759)$ & $<0.01$ \\
Synthetic colloid fluid, ml & $1733(459)$ & $1351(450)$ & $<0.01$ \\
Total crystalloid fluid, ml & $2687(735)$ & $2886(580)$ & 0.25 \\
Ringer's acetate, ml & $737(337)$ & $1738(477)$ & $<0.01$ \\
Buffered 2.5\% dextrose & $1472(595)$ & $731(363)$ & $<0.01$ \\
Other crystalloids & $478(76)$ & $417(256)$ & 0.04 \\
Plasma, $\mathrm{n}, \mathrm{ml}$ & $3[280-1611]$ & $2[784-1050]$ & 1.00 \\
Erythrocytes, $\mathrm{n}, \mathrm{ml}$ & $6[267-1121]$ & $3[330-849]$ & 0.47 \\
Thrombocytes, $\mathrm{n}, \mathrm{ml}$ & $2[235-280]$ & 0 & 0.49 \\
Albumin 4-5\%, $\mathrm{n}, \mathrm{ml}$ & $11[250-1750]$ & $6[250-750]$ & 0.25 \\
Albumin 20\%, $\mathrm{n}, \mathrm{ml}$ & $2[100-100]$ & $5[100-200]$ & 0.25 \\
Measured Intraoperative & $3631(936)$ & $3257(867)$ & 0.18 \\
Fluid balance, ml & $12[552-9640]$ & $9[2000-8160]$ & 0.56 \\
Phenylephrine, $\mathrm{n}, \mu \mathrm{g}$ & $26[172-2606]$ & $21[407-3378]$ & 0.15 \\
Norepinephrine, $\mathrm{n}, \mu \mathrm{gg}$ & $27[4-257]$ & $9[20-71]$ & $<\mathbf{0 1}$ \\
Dobutamine, $\mathrm{n}, \mathrm{mg}$ & $2.1[1.0-3.1]$ & $2.0[1.1-2.9]$ & 0.61 \\
Dobutamine, rate during & & & \\
infusion, $\mu \mathrm{g} \mathrm{kg}{ }^{-1} \mathrm{~min}{ }^{-1}$ & & & \\
\hline
\end{tabular}

\section{Postoperative complications, bowel recovery and length of stay}

There was no mortality during the 30 day observation period. Postoperative complications are listed in Table 9. In the intervention group the incidence of complications per patient after 30 days was 4 [2-6] (median [IQR]) compared to 2 [1-4] in the control group $(P=0.10)$.

There were no significant differences in recovery of bowel function i.e. time to first passage of flatus, first bowel movement or duration of intravenous maintenance fluid.

Length of hospital stay was 20 days [15-45] (median [IQR]) in the intervention group and 18 days $[15-25]$ in the control $(\mathrm{P}=0.41)$. Length of ICU stay including readmissions was 67 [44-103] (median [IQR]) hours in the intervention group compared to 42 [23-67] hours in the control group 
$(\mathrm{P}=0.03)$. Nine intervention and five control patients were readmitted to the ICU $(\mathrm{P}=0.20)$.

Table 9. Postoperative complications within 5 and 30 days after surgery. ${ }^{a}$ including tracheobronchial injury, unplanned gastroscopy, pneumothorax.

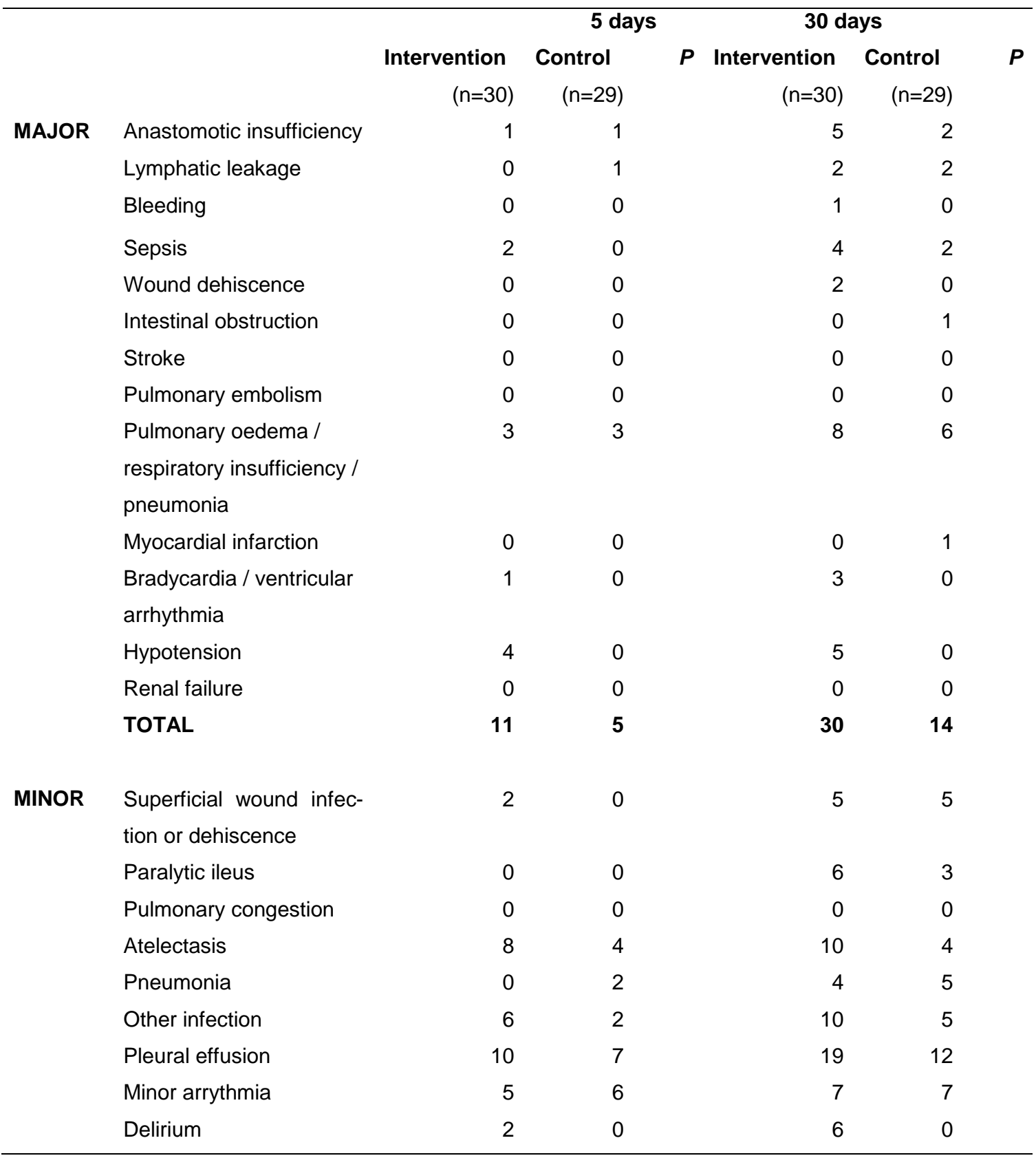




\begin{tabular}{|c|c|c|c|c|c|c|}
\hline Deep vein thrombosis & 0 & 0 & & 0 & 0 & \\
\hline Renal dysfunction & 1 & 0 & & 4 & 2 & \\
\hline Coagulopathy & 6 & 4 & & 7 & 5 & \\
\hline TOTAL & 40 & 25 & & 78 & 48 & \\
\hline & 5 & 3 & & 16 & 19 & \\
\hline ber of complications & 56 & 33 & & 124 & 81 & \\
\hline $\begin{array}{l}\text { of complications per } \\
\text { ledian (IQR)) }\end{array}$ & $2(0-3)$ & $1(0-2)$ & 0.10 & $4(2-6)$ & $2(1-4)$ & 0.10 \\
\hline
\end{tabular}

Total number of complications

Incidence of complications per patient (median (IQR))

There are liars, there are outrageous liars, and there are scientific experts.

Sir Robert Giffen

Knowledge is as wings to man's life, and a ladder for his ascent. (...) Great indeed is the claim of scientists and craftsmen on the peoples of the world ... In truth, knowledge is a veritable treasure for man, and a source of glory, of bounty, of joy, of exaltation, of cheer and gladness unto him.

Bahá'u'lláh 


\section{DISCUSSION}

The goal of the thesis is to contribute to an increased understanding of GDFT when applied clinically during major abdominal surgery, by evaluating the prevalence and impact of preoperative dehydration, assessing the potential of a total non-invasive device for GDFT to replace a more cumbersome and invasive reference technique, and by confirming the beneficial results of GDFT based on pulse contour analysis when applied in a surgical cohort with a high risk of postoperative complications even in modern healthcare. Based on the literature available at the time of designing the thesis, considerable optimism about both the internal validity and clinical impact of stroke volume optimisation and the use of dynamic parameters characterised the design of the studies involved.

Clearly, the findings of this thesis indicate challenges when the concept of GDFT is applied in clinical routine. This is indicated by the fact that different methods for GDFT (i.e. PVI and oesophageal Doppler) had low concordance for determining the need for and effect of a fluid bolus. It is also indicated by the fact that SVO using both oesophageal Doppler and FloTrac had internal limitations. Only a minority of indicated fluid boluses lead to a significant increase in SV (i.e. a substantial false positive rate), some fluid boluses which were given despite not being indicated according to the algorithm (but were indicated according to the other (PVI)) did result in an significant increase in SV (i.e. a substantial false negative rate), and "illogical" responses occurred, e.g. a first fluid bolus without a significant effect on SV followed by a second fluid bolus causing a significant increase. Finally, even though we did not find any difference in clinical outcome when GDFT using PVI or oesophageal Doppler was compared, GDFT in oesophageal resection patients did not result in a more favourable postoperative outcome. On the contrary, the associated increased colloid load and increased use of dobutamine were associated with a trend towards an increased incidence of complications and a prolonged length of stay in the ICU.

\section{Stroke volume optimisation}

As mentioned previously, the concept of stroke volume optimisation is primarily a clinical application of the Frank-Starling law of the heart, by 
analysing the effect of fluid boluses on SV. In order for this adaptation of the Frank-Starling law to be true, the following conditions have to be met: 1. The fluid bolus has to result in a predictable and significant increase in plasma volume.

2. This increase in plasma volume has to lead to a significant and predictable increase in venous return to the right heart.

3. This increase in venous return to the right heart has to result in a significant and predictable increase in end-diastolic filling of the left ventricle.

It is unknown whether these conditions are met under normal circumstances. However it is probably valid to say that an increase in SV after a fluid bolus most likely means that the patient is on the steep part of the Frank-Starling curve, if all other circumstances are unchanged. An absence of effect on SV however does not prove that the patient is on the flat part of the Frank-Starling curve (see below).

\section{Common arguments against SVO}

\section{"Fhid responsiveness is physiological"}

One common criticism against the SVO concept is the claim that in healthy people at rest the heart does not operate on top of the FrankStarling curve and therefore is fluid responsive, i.e. healthy people will increase SV when given an intravenous fluid bolus. This implies that a positive response to a fluid bolus during surgery does not mean that that fluid was needed or beneficial. This viewpoint is not supported by evidence. Bundgaard-Nielsen et al. measured SV using oesophageal Doppler in 20 healthy awake subjects before and after a $200 \mathrm{ml}$ colloid fluid bolus. None of the subjects increased SV with $10 \%$ or more. 39 Godfrey et al. showed a significant increase in SV as monitored by transthoracic echocardiography, when performing passive leg raising (PLR) in 5 of 11 healthy subjects, $4^{40}$ however mean increase in SV was below 10\%. Furthermore PLR in awake subjects may not be a good model since other factors such as changes in vasomotor tone may occur. ${ }^{41}$

Subjects not showing an increase in SV after a fluid bolus do not invariably need to operate on the flat part of the Frank-Starling curve. An alternative, more likely explanation in healthy patients is that the fluid bolus fails to increase venous return enough to cause a sufficient increased filling of the left ventricle. This could be related to either the fluid bolus increasing the "unstressed" blood volume but not the "stressed" volume which has the capacity to change venous return, or because the 
increase in stressed blood volume is being offset by an increase in CVP, causing an unchanged gradient for venous return..$^{2}$ In reality, these are probably simultaneous processes. However, with both explanatory mechanisms, a sustained increase in SV after a fluid bolus in a surgical patient should be considered a sign of hypovolemia.

\section{"The increase in SV and thus CO after a fluid bolus is caused} by haemodilution, and therefore $\mathrm{DO}_{2}$ does not increase significantly even if CO does". 43

Infusion of a fluid bolus can be expected to decrease $\mathrm{Hb}$ and thus viscosity, which in its turn could cause increased CO. A $3 \mathrm{ml} / \mathrm{kg}$ fluid bolus in a patient with a blood volume of $70 \mathrm{ml} / \mathrm{kg}$ can be expected to dilute the blood by about $4 \%$, (supposing perfect mixing conditions). This would diminish but not abolish the increase in $\mathrm{DO}_{2}$ caused by an increase in $\mathrm{CO}$ of $10 \%$ or more. Also conflicting data exists on whether cardiac output increases during limited acute normovolemic haemodilution, and whether its magnitude is sufficient to explain an increase in $\mathrm{CO}$ of $10 \%$ or more. 44 45

\section{"Surgery doesn't last a lifetime".}

Even if a fluid bolus would increase SV, $\mathrm{CO}$ and $\mathrm{DO}_{2}$, this only applies to that short intraoperative moment. Later on during surgery, and especially after surgery when the patient has been extubated and transferred to the PACU or ICU, circumstances such as vascular tone and right ventricular afterload will have changed dramatically, causing the patient which might have been optimally filled during surgery now to be hypervolemic. Therefore it might be wise to accept some slight intraoperative hypovolemia in order to avoid a significant postoperative hypervolemia. 46

\section{"SVO leads to fluid overload in patients with healthy hearts."} As mentioned above a fluid bolus probably does not cause a significant and sustained increase in SV in most healthy awake subjects. The reason is not that these subjects are on the top of their Frank-Starling curve, but that venous return is not permanently increased by the fluid bolus, possibly because of venous stress relaxation. 47 Venous return is controlled by the peripheral tissues based on metabolic demands, 4849 and by way of venous stress relaxation a temporarily increased venous return and thus $\mathrm{CO}$ is adjusted again to a level sufficient for the amount of oxygen needed. This means that when a fluid bolus is given rapidly, a transient increase in SV can be seen in those patients who are not at the top of the FrankStarling curve and who have no unmet metabolic demands (e.g. many 
surgical patients in modern settings) (Fig 16). This probably only reflects the cardiac reserve of the patient, not the need for additional fluids. $5^{\circ}$

Figure 16. Significant but unsustained increase in SV (upper line) and CI (lower line) after a fluid bolus. The time scale for the whole image is 30 minutes.

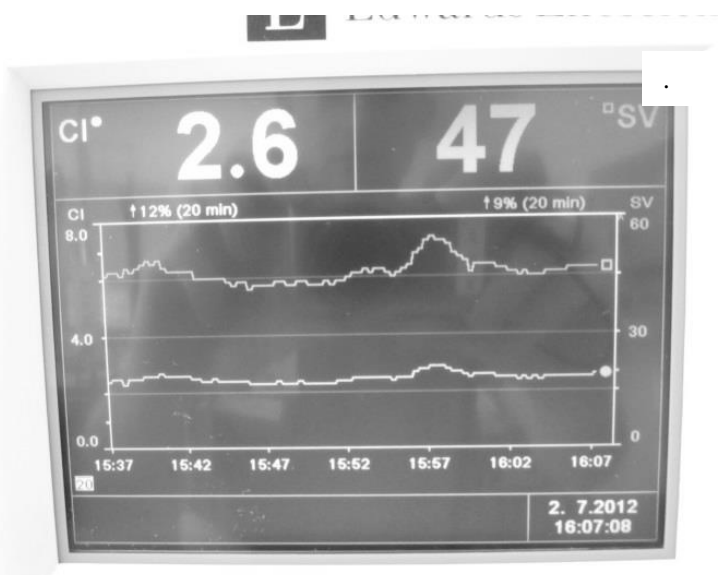

Unpublished data from the author.

Clearly if such a patient is classified as a responder and more fluids are given this will lead to iatrogenic fluid overload, as was probably the case in the study by Challand et al..$^{1}$ However, even when allowing sufficient time before classifying a patient as responder, a strict application of SVO during prolonged and haemodynamically demanding surgery can result in fluid overload, as shown in Study IV.

\section{"Fluids should not be given as boluses anyway".}

In order to be able to evaluate the effects of a fluid bolus on SV, the fluid bolus has to be given moderately rapidly, i.e. over a few minutes or even faster. There are however two disadvantages entailed with this: Firstly, the plasma expanding effect of infusion of any fluid is time dependent, i.e. the slower an infusion is given, the longer the plasma expansion will last. $5^{2}$ Secondly, giving fluids in a short time could lead to vascular stretch, and this has been associated with damage to the so-called glycocalyx and thus an increase in capillary permeability. However, the clinical importance of this phenomenon is unclear. 53 


\section{Dynamic parameters}

There are several theoretical advantages of dynamic parameters compared to SVO. With SVO, a fluid bolus needs to be given first to determine whether a patient is fluid responsive. This means that many fluid boluses will be given with no benefit and possibly causing harm, as shown in Studies I and IV. With dynamic parameters no fluid is given when the parameter is below a certain value. Also, since many dynamic parameters can be measured completely non-invasively (e.g. using PVI) this would significantly simplify fluid management in large patient groups. Research interest in these techniques has therefore been substantial.

There are also disadvantages with dynamic parameters.54 Firstly the interactions between the respiratory and circulatory systems are far more complex then described in the Introduction: for instance, during mechanical inflation, besides a decrease in venous return there simultaneously occurs an increase in right ventricular afterload, a transient increase in left ventricular preload, and a decrease in left ventricular afterload. ${ }^{55} \mathrm{Sec}-$ ondly, in order for dynamic parameters to be usable, respiratory and circulatory changes have to be regular: this requires sinus rhythm, absence of a significant amount of irregular beats and controlled mechanical ventilation without spontaneous respiratory effort. Thirdly changes in pulmonary and chest wall mechanics (fibrosis, obesity, thoracotomy) will influence the effect of intrapulmonary pressure changes on extrapulmonary structures such as the heart. This was the reason why we chose SVO using pulse contour analysis in Study IV. Also a sufficiently large tidal volume is required, which might be larger than that considered protective ventilation or acceptable during one-lung ventilation. $5^{6}$ According to some, these conditions are met in less than $40 \%$ of surgical patients. ${ }^{57}$ Also, an absolute cut-off value has to be chosen, with optimal values reported to be between $6-20 \%$ depending on the device and the particular experimental conditions. Choosing a low cut-off value will lead to larger volumes of fluid being given, while a high cut-off value will result in more restrictive fluid administration. For this reason a "grey zone approach" has been advocated where fluids should be given above a certain cut-off value, should not be given below another (lower) cut-off value and might be given on values between these two (the grey zone), depending on circumstances. ${ }^{36}$ The percentage of patients in the grey zone however varies between studies and is sometimes substantial, as in our material (Study I). 58 


\section{Limited agreement between measuring devices}

Clearly, since different GDFT devices operate on very different principles, a perfect concordance cannot be expected, and smaller differences in results should not invalidate the application of these devices in GDFT. Since reliable methods for measuring $\mathrm{CO}$, such as surgically implanted aortic flow probes, are not available in clinical practice, many devices have during their early phases been compared with the PAC. However the PAC is an unprecise device itself, 59 and it is therefore no surprise that the differences between these newer devices sometimes are quite large, as illustrated by the limited concordance between PVI and oesophageal Doppler in Study I.

It is even more troubling when monitors disagree on the direction of change of SV or CO. Due to the setup of our studies this could not be analysed in our material but e.g. Meng et al. compared readings of oesophageal Doppler with FloTrac in patients receiving fluids, ephedrine (a combined inotropic, chronotropic and vasoconstrictor) or phenylephrine (a selective vasoconstrictor). ${ }^{60}$ Concordance was high when patients received fluids, lower when patients received ephedrine and very low when patients received phenylephrine. In the latter group, in most patients the increase in blood pressure caused by the vasoconstrictor was interpreted as an increase in $\mathrm{CO}$ by FloTrac, while $\mathrm{CO}$ decreased according to oesophageal Doppler.

\section{Specific challenges for PVI, oesophageal Doppler and FloTrac. \\ PVI}

Besides the general limitations of dynamic parameters as mentioned above, there are some factors which have been described to influence measurement of PI and thus PVI. One of these is local sympathetic tone: Bergek et al. performed brachial plexus blocks and reported increased PI and decreased PVI measured on the affected hand while measurements were unchanged on the non-affected side. ${ }^{61}$ In general sympathetic tone is known to vary cyclically, and since surgical intensity varies during a procedure, this variation can be expected to be even larger. ${ }^{62}{ }^{63}$

Also vasoconstrictors, used in a majority of our study patients, have, at least in an ICU setting, been reported to decrease the performance of PVI for predicting fluid-responsiveness. ${ }^{64}$ 
Regarding non-invasive measurement of $\mathrm{Hb}$, Study II confirms previous reports that non-invasive $\mathrm{Hb}$ measurements differ too much from invasively measured $\mathrm{Hb}$ to be used in volume kinetics. ${ }^{65}$

\section{Oesophageal Doppler}

The main advantage of oesophageal Doppler is that it measures blood flow velocity centrally in the descending aorta, and thus is not influenced in any way by peripheral conditions influencing more distal cardiac output monitors. However besides practical difficulties with the device mentioned previously such as instability of the signal, the need of frequent repositioning and disturbances caused by diathermy or other electric devices, the method has some further limitations. Firstly the ultrasound signal is stated to be sent at a $45^{\circ}$ angle towards the aortic flow, but in reality alignment between the probe and the aorta will probably not be perfect. Therefore this angle will vary which will influence the calculation of blood speed. ${ }^{66}$ Secondly, aortic diameter is not measured but calculated, and local changes such as stenosis will cause significant errors in flow calculation. Thirdly, the fraction of CO not passing the descending aorta (exiting the aortic arch towards head and arms) is assumed to be constant, however this is probably not the case. ${ }^{67}$

\section{FloTrac}

The key question for FloTrac is whether pressure waves at the distal site of measurement are adequate, undisturbed reflections of central blood pressure, and whether it is able to adequately interpret this local pressure wave and convert it into flow.

Clearly, local upstream impediments to flow in e.g. the radial artery caused by anatomical (stenosis) or pharmacological (excessive dose of vasoconstrictor) factors will influence calculation of CO. Likewise, a decreased peripheral resistance downstream in the hand, e.g. by forced air heating and/or a high thoracic epidural block, has been reported to result in a increased gap between central and distal mean arterial blood pressure. This could be expected to influence CO readings. 686970 However studies have not shown major differences between $\mathrm{CO}$ measurements from radial and femoral arterial lines, at least during and after cardiac surgery. ${ }^{71}{ }^{72}$ Femoral and radial mean arterial pressures were similar in these studies though. 


\section{Besides fluids: inotropes and vasoconstrictors}

\section{Inotropes}

Increasing plasma volume by fluid boluses is no end in itself but a way to obtain a more adequate $\mathrm{CO}$, which in its turn is a prerequisite for an adequate $\mathrm{DO}_{2}$. Therefore many GDFT strategies contain a target value for cardiac index (CI), which is $\mathrm{CO} /$ body surface area (BSA). In older studies a CI of around $4.5 \mathrm{l} / \mathrm{min} / \mathrm{m}^{2}$ was needed to obtain the target $\mathrm{DO}_{2}$ with reasonable $\mathrm{Hb}$ values. More recent studies usually use a minimal $\mathrm{CI}$ value of $2.5 \mathrm{l} / \mathrm{min} / \mathrm{m}^{2}$. Since many patients do not reach this CI target with fluids alone, inotropes such as dobutamine or dopexamine, which increase cardiac contractility, are often used to obtain a CI of $2.5 \mathrm{l} / \mathrm{min} / \mathrm{m}^{2}$ or more in patients deemed to be optimally filled. In Study IV dobutamine was needed in 27 of 30 patients to maintain the target $\mathrm{CI}$ of at least $2.5 \mathrm{l} / \mathrm{min} / \mathrm{m}^{2}$. However catecholaminergic inotropes increase cardiac oxygen consumption and can thus lead to side effects such as cardiac ischaemia, and some studies have found an overall negative effect of inotropes in patients undergoing cardiac surgery or in patients with heart failure.73

While some studies report beneficial effects of inotropes in abdominal surgery, 74 Davies et al. reported no benefit of the addition of a low dose of dopexamine to stroke-volume optimised patients, reflecting earlier findings by Takala et al. $75{ }^{76}$ Pavlovich reported worse outcome in emergency surgical patients randomised to a GDFT protocol including a target CI of $2.5-3 \mathrm{l} / \mathrm{min} / \mathrm{m}^{2}$ which necessitated dobutamine in about $50 \%$ of patients, compared to patients who were only fluid-optimised guided by the dynamic parameter PPV.73 Therefore, although recommended by several reviews, ${ }^{12}$ and part of ongoing trial protocols (https://optimiseii.org/ documents), the role of inotropes in GDFT remains unclear.

\section{Vasoconstrictors}

Anaesthetic drugs cause venous vasodilation which in its turn causes a "relative hypovolemia" resulting in decreased venous return and thus decreased $\mathrm{CO}$. These drugs also cause arterial vasodilation and thus decreased arterial resistance, which results in decreased arterial pressure even if $\mathrm{CO}$ is maintained.

These effects can be mitigated by increasing plasma volume with fluids. However, when the anaesthetic drugs are discontinued at the end of surgery, vascular tone will return and the fluids given earlier will now result in hypervolemia. Therefore it seems prudent to at least partially counteract the vasodilation caused by anaesthesia with specific vasoconstricting drugs. However these drugs do have side-effects such as tachycardia, 
and when given in too high dose could result in decreased local blood flow through exaggerated vasoconstriction. Also, $\mathrm{CO}$ is known to decrease when arterial resistance increases in patients with left ventricular failure. Despite these possible drawbacks, the few randomised studies published report positive results of the use of low doses of vasoconstrictors during abdominal surgery. ${ }^{77}$ In Studies I and III vasoconstrictors were used in most and in Study IV in all patients. In the specific case of oesophageal resections, reported use of vasoconstrictors varies from "rarely necessary" 78 to being used routinely. 79

\section{Preoperative dehydration}

Study II showed that on average preoperative dehydration in elective surgical patients in our setting was limited. However those patients who were dehydrated handled an intravenous fluid load in a significantly different way compared to euhydrated patients. Combined with other reports showing a correlation between preoperative dehydration and postoperative complications, ${ }^{80} 81$ this might imply that adapting intraoperative fluid treatment to preoperative hydration status could be beneficial. However in what way fluid treatment should be adapted is unclear. Also, the urinary analysis described in this thesis for diagnosing dehydration is difficult to use to guide intraoperative treatment as long as some of the parameters cannot be assessed bedside. It might be worthwhile to find a way of assessing dehydration which can be performed bedside and evaluating the effect of adapting intraoperative fluid administration accordingly.

Fluid kinetics could also be used to diagnose dehydration, however serial invasive $\mathrm{Hb}$ measurements after a fluid bolus are unpractical in routine practice and the non-invasive measurement of $\mathrm{Hb}$ is at the moment not reliable enough as mentioned previously.

The findings in Study II showing different fluid kinetics of a fluid bolus in euhydrated and dehydrated patients could be perceived to be in conflict with the fact that we found no correlation between dehydration index and the volume of colloid given during induction and the first optimisation round. The latter result seems to indicate that the moderate dehydration in our cohort does not influence plasma volume, as has been suggested by others. ${ }^{82}$ We can only speculate that there are other factors related to hydration status beside plasma volume that influence the distribution of a crystalloid fluid load. 


\section{Is GDFT evidence-based?}

As mentioned previously, the present studies were designed with confidence in the benefit of GDFT. This was the reason for having no controlgroup without GDFT in Studies I-III and for the presumptions in the sample size calculation in Study IV. This confidence was based on the initial reports on GDFT which showed impressive clinical results, and these, possibly combined with potential economic benefits for manufacturers of devices applied during GDFT, resulted in a large number of studies being published on the subject. However not all of these have been able to confirm the beneficial effects of GDFT, including the relatively recent OPTIMISE study, to this date the largest in the field. ${ }^{83}$ Still, a rapidly increasing number of meta-analyses conclude virtually without exception that GDFT has beneficial effects on clinical outcome. Some studies, using a technique called trial sequential analysis, report that these findings are definite and that more studies on this topic are not needed.848586 Other authors however are still sceptical, pointing out that many modern studies have been negative, that many studies are of low methodological quality and that the positive effect found in meta-analyses actually could reflects bias on different levels of the scientific process. ${ }^{46} 87$ Also, some recent meta-analyses point out that the effects of GDFT in patients managed using modern fasttrack pathways such as ERAS are limited. ${ }^{88}$ This causes some authors to call for more large-scale studies, while others start to wonder whether traditional science will ever find an answer to this question and recommend starting spending resources on making adequate care reliably available, instead of "chasing ever-decreasing marginal gains."89 9o Several large clinical trials on GDFT, such as FLO-ELA (using several devices) (www.floela.org) and Optimise II (using FloTrac or Clearsight) ${ }^{91}$ are ongoing.

\section{GDFT studies and fluid restriction}

It is well known that both overly liberal and overly restrictive perioperative fluid infusion increase the risk of postoperative complications. ${ }^{92}$ In modern clinical practice fluid overload seems to be more common than too little fluid, despite the attention being given to the deleterious effects of fluid overload.993 Interestingly, in the beginning of the GDFT era it was argued that common parameters such as heart rate and blood pressure could be normal despite significant hypoperfusion, ${ }^{13}$ and therefore GDFT was expected and reported to result in the administration of larger volumes of fluids, especially colloids, compared to controls. ${ }^{94}$ This is reflected by Study IV where the intervention group received a significantly larger volume of colloids and a (non-significantly) increased total fluid infu- 
sion. However modern GDFT therapies are often associated with a reduction in total perioperative fluid administration, even though colloid use is often increased (Fig. 17). ${ }^{86}$

Figure 17. Difference in total fluid administration between intervention and control groups versus odds ratio for postoperative complications in the intervention group compared to controls. Data from 11 trials on GDFT using uncalibrated pulse contour methods in abdominal surgical patients. The large dot represents Study IV.

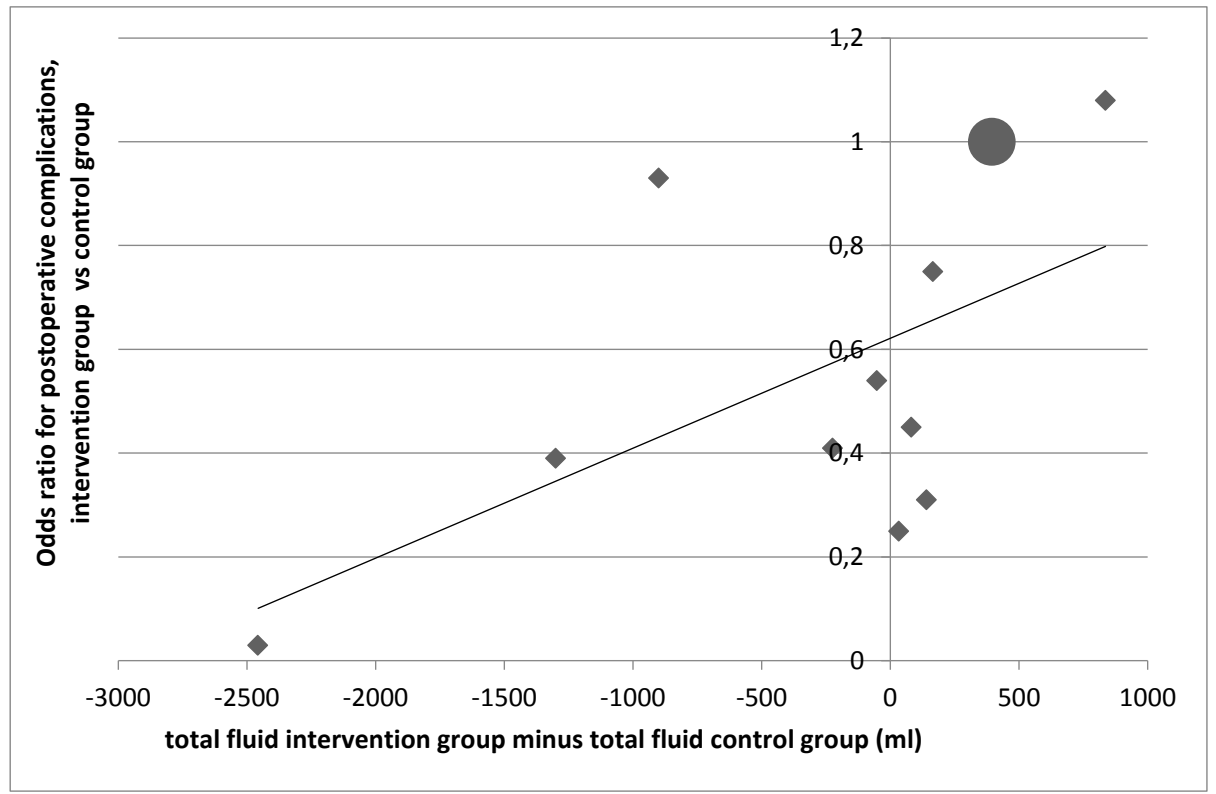

Data from Michard 2017.86

This raises the question whether the beneficial effects of GDFT reported in some modern trials could actually be caused by the associated reduction in total fluid administration compared to controls, and not the GDFT per se. In that case the same clinical benefit could be obtained by using more restrictive fluid algorithms without the need for additional monitoring equipment. As mentioned previously, GDFT has not been shown to be beneficial in patients treated in an ERAS setting, which includes the avoidance of large volumes of intravenous fluids, 95 and a study explicitly comparing GDFT with a zero balance fluid approach found no difference in clinical outcome. ${ }^{6}$ Another illustrative example is the study by Colantonio et al. 97 in patients undergoing cytoreductive surgery combined with hyperthermic intraperitoneal chemotherapy, where the control group received on average over eight litres of fluid intraoperatively. Even 
if fluid needs can be expected to be increased with this specific type of surgical intervention, any strategy with or without GDFT which leads to a decrease in such a fluid overload can be expected to improve outcome. Still the improved outcome is attributed to the GDFT, and these conclusions also influence subsequent meta-analyses. Thus, the amount of fluid given to the control group might be an important factor when designing and evaluating trials on GDFT.

\section{Limitations}

Factors influencing the predictive capacity of PVI (Studies I \& III)

In Study I we found a limited capacity of PVI to predict an increase in SV after a fluid bolus as assessed by oesophageal Doppler. Some factors have been reported to influence the predictive value of PVI. Broch et al. $9^{8}$ reported an increase in predictive value of PVI when only higher PI values were considered ( $>4 \%$ ), which was found in approximately half of their patients. We did record though not report PI values in our studies, and analysed the data regardless of PI values, reflecting the clinical practical design of our work. PI was $>4$ in $60 \%$ of measurements in Study I.

Also the site of measurement could influence the performance of PVI. Measurements on the forehead usually result in better performance compared to finger or ear measurements. 99100

Finally performance of dynamic parameters is improved by using larger fluid boluses and larger tidal volumes. We used fluid boluses of 3 $\mathrm{ml} / \mathrm{kg}$ up to $250 \mathrm{ml}$ and feel that larger fluid boluses would lead to fluid overload in this setting, where fluid boluses were expected to be used repeatedly throughout surgery. Most studies using $500 \mathrm{ml}$ boluses only gave one fluid bolus, and most were performed in an ICU setting.

We used a tidal volume of $7 \mathrm{ml} / \mathrm{kg}$ IBW in line with our clinical routine. In many studies it is not clear whether actual or ideal bodyweight is used, but many recommend a tidal volume of at least $8 \mathrm{ml} / \mathrm{kg} .{ }^{101}$ This is higher then recommended for protective ventilation during surgery, ${ }^{102}$ and to what extent this will offset the benefit of increased performance of dynamic parameters is unknown.

\section{Categorical comparison between PVI and oesophageal Doppler using Cohen's kappa (Study I)}

One could argue that our way of comparing PVI and oesophageal Doppler for assessing the indication for and effect of a fluid bolus, as well as as- 
sessing their predictive capability for fluid responsiveness, is too stringent. For example, if PVI during surgery increased from 9 to $11 \%$, while $\mathrm{SV}$ at the same time decreased $8 \%$, this was classified as (fluid bolus) indicated according to PVI but not-indicated for SV, while one could argue that the methods were "quite close". Similarly, if SV after a fluid bolus increased from 60 to 66 this would be defined as fluid responsiveness, while an increase from 60 to 65 would be defined as non-fluid responsiveness. Usually, when comparing trending ability of two CO monitors, cases with small changes are usually excluded, since in these cases measurements can be very close but still point at an opposite direction. ${ }^{103}$

Our reasons for choosing this stringent categorical approach were that 1. PVI and SV are different parameters, thus it is not straightforward to define equally small and large changes for both of them, as one would be able to do when comparing two devices for measuring SV; 2 . the cut-off value of $10 \%$ for changes in SV does not reflect clinical significance. Instead it is based on precision of measurement by the oesophageal Doppler; thus changes $<10 \%$ might not reflect changes at all (https://www.deltexmedical.com/us/product/edmplus/accuracyprecision/), and 3. The decision of a clinician to administer a fluid bolus is also categorical: fluid is either given or not. As mentioned above, the greyzone strategy has been claimed to solve this latter issue, however in our opinion only to a very limited degree.

Nevertheless, the concordance analysis could have been expanded with some form of (qualitative?) quantification of the agreement or disagreement between the methods.

\section{Definition of dehydration (Study II)}

In Study II volume kinetics were compared in the dehydrated group and the hydrated group. Patients were classified as dehydrated if they had a Dehydration Index (composed of 4 urinary measurements) of $>3.5$. However dehydration is not a yes or no phenomenon. In a previous work, a DI of 4 was used as a cut-off for indicating dehydration. 33 The cut-off value of $>3.5$ in Study II was chosen post-hoc based on the calculated DI's, in order to have a sufficient number of patients in both groups, since only 4 patients had a DI of 4 or higher.

\section{Superiority vs equivalence / non-inferiority}

Study IV is classical superiority trial, i.e. our hypothesis was that goaldirected fluid treatment would result in a better postoperative outcome. In Study III however, we stated that "We hypothesised that there would 
be no difference between the groups [PVI vs OD] regarding these parameters." Thus, one could argue that this would call for an equivalence trial, where the (alternative) hypothesis is that the "new treatment" is neither significantly worse nor better than the standard treatment. However equivalence trials are primarily used to compare pharmacokinetic profiles of newer drugs compared to old ones, and are sometimes described to be not suitable for clinical trials. ${ }^{104}$ Instead, in these settings non-inferiority trials are usually used, where the (alternative) hypothesis is that the new treatment is not significantly worse than the old. ${ }^{105}$

For these trials, a "maximally acceptable worse effect" ( $\Delta_{\text {non-inferiority }}$ $\left(\Delta_{\text {ni }}\right)$ needs to be chosen, amongst others for determining whether the null-hypothesis can be rejected, and according to many the choice of $\Delta_{\mathrm{ni}}$ needs to be justified. However others claim that choosing $\Delta_{\text {ni }}$ is similar to choosing the smallest significant effect in superiority studies, and that the outcome of a non-inferiority trial should not be measured by whether the null-hypothesis can be rejected but by looking at the actual effect and its confidence interval. ${ }^{106}$ They also claim that a non-inferiority study does not automatically necessitate a larger sample size, as long as $\Delta_{\text {ni }}$ is equal to the corresponding smallest significant effect in superiority studies.

Another difference between superiority and non-inferiority trials is that in superiority trials, an intention-to-treat analysis is considered the most robust. This means that all patients receiving the intervention are counted in, not taking into account protocol violations, which in theory would decrease the effect of a treatment. On the contrary, in noninferiority trials, including patients with protocol violations increases the chance of finding no difference between treatments. Therefore some advocate that in these cases a per-protocol analysis should be done, where only patients that have been treated fully according to protocol are included. In two PVI patients in Studies I and III access to oesophageal Doppler data was requested and given for clinical reasons; these might be excluded in a per-protocol analysis. Others however argue that to establish which patients have been treated according to protocol is highly subjective and therefore should not be done even in non-inferiority studies.

Returning to Study III, it possibly should have been called a noninferiority study. However, contrary to our statement in the discussion section of the published paper, it is not certain this would have entailed a larger sample size. An intention to treat analysis might have been added though, as well as a confidence interval. 


\section{The application of composite endpoints (Studies III and IV)}

In both Study III and IV clinical outcome in intervention and control groups was measured by counting the incidence of a number of predefined postoperative complications. The list of complications was modified before each study from the landmark study by Brandstrup et al. ${ }^{107}$

Composite outcomes increase statistical power and might give a better picture of the effect of an intervention compared to using one single parameter as outcome, however certain caveats apply. ${ }^{108}$ Most importantly, the different components should reflect approximately similar severity; if not, especially in combination with large differences in incidence, an intervention resulting in a few but very severe complications might appear favourable compared to a control group with a multitude of insignificant complications. It can therefore be discussed whether it was appropriate for Studies III and IV to analyse minor complications such as non-septic infection together with major complications such as stroke and myocardial infarction.

Also, if the occurrence of selected components is influenced in different directions, statistical power decreases. This could be applied to the fact that both pulmonary congestion and hypotension were scored as components; these complications are typically assumed to be associated with hyper- and hypovolemia respectively.

The above mentioned challenges can be compensated for by using more advanced multivariate methods such as the common effect test or the distinct effect test. ${ }^{108}$ However in Study III the total number of complications in each group was reported as the main outcome, and in Study IV the median number of complications per patient, both analysed using the Mann-Whitney $U$-test, thus possibly losing information on heterogeneous treatment effects of the different components.

Still, based on the actual results as presented in detail in Table 7 (Study III) and Table 9 (Study IV), we do not think that the abovementioned issues have significant bearings on the conclusions of the studies, but we agree with Mascha and Sessler ${ }^{108}$ on the importance of carefully selecting the components of a composite outcome as well as the statistical tests to analyse the results. However, perfectly adapting the statistical strategy to the patient population in each individual study makes comparisons with other studies more challenging. 


\section{Future perspectives}

Based on the findings of this thesis and other research, showing both methodological issues and uncertainties about the clinical benefit of GDFT, it is unlikely that a strict application of any single-value strategy, such as optimisation of SV, PVI, and/or $\mathrm{DO}_{2}$ by any specific monitor, will lead to clinical benefit in all patients and under all conditions. Therefore, we suggest that the elements of GDFT are incorporated in the general clinical management of high-risk patients, i.e. the decision to administer fluids and/or inotropes should be based on a holistic assessment of the patient, including data on SV and dynamic parameters but also blood pressure, fluid balance, lactate etc. Information on preoperative hydration status should also be sought. In many instances some of these parameters will contradict each other, and thus the decision to administer or refrain from more fluids will always to some extent depend on the subjective judgement of the practitioner.

In the vast majority of surgical patients a safe anaesthetic can be provided without access to measurement of $\mathrm{CO}$ or dynamic parameters. However in some high risk cases measurement of $\mathrm{CO}$ might still be of benefit, especially to investigate the reason for intraoperative hypotension.

We suggest that future studies should further investigate whether peripheral blood pressure measurements (e.g. in the radial artery) present an adequate assessment of central blood pressure during haemodynamically challenging surgery, and thus, as a corollary, whether calculation of $\mathrm{CO}$ based on these peripheral blood pressure measurements are reliable.

Also, the benefits of preemptive treatment of preoperative dehydration need to be confirmed. Given the limited degree of overall dehydration in our population, the question remains whether more fluids should be given to all patients before surgery (e.g. by infusion of approximately 1.5 liter of crystalloid the night before surgery) ${ }^{31}$ or whether this only should be applied to patients deemed to be significantly dehydrated. In these patients, e.g. those with severe ileus, it is also unclear whether a rapid or a more slow correction of the fluid deficit should be aimed for.

Finally, since the veins contain most of the blood in the human body, a more complex perspective on haemodynamics focusing on factors determining venous return could in theory lead to a more adequate description of a patients' circulatory state. ${ }^{109}$ However reliable measurements of blood pressure, CO and CVP are required for this model, and therefore the clinical benefits of this model are at the moment unknown. 
I'm coming to the end now, slowly but surely. Thank God, someone will say. Nescio 


\section{CONCLUSIONS}

\section{Study I}

1. The concordance between PVI and oesophageal Doppler for assessing the indication for and the effect of a fluid bolus during open abdominal surgery was low.

2. Both methods only had a limited capacity to predict fluid responsiveness.

3. The amount of fluid given for volume optimisation did not differ between the groups.

\section{Study II}

1. General level of dehydration before elective major open abdominal surgery was moderate.

2. Dehydrated patients had a slower distribution of fluid from the central to the peripheral compartment. Other kinetic parameters did not differ.

3. Volume kinetics cannot be reliably measured using non-invasive Hb-measurements.

\section{Study III}

1. Patients receiving GDFT based on PVI during major open abdominal surgery had similar number of complications and length of stay compared to patients receiving GDFT using oesophageal Doppler.

\section{Study IV}

1. GDFT based on FloTrac did not result in a decreased incidence of complications, shorter hospital stay or shorter return of bowel function in patients having elective oesophageal resection compared to a control group. The intervention was associated with an increased length of stay on the ICU. 


\section{ERRATA IN PUBLISHED ARTICLES}

\section{Study I}

Page 185 Table 1 last line. Should read: “... whether this first fluid bolus was indicated or not according to Doppler.”

Page 187 Table 2 second last line. "Proportion" should read "Percentage" (both occasions).

Page 189 Table 3. Number and range of neosynephrine in the Doppler group. "11 640" should read "6 640".

Supplemental Figure S1. This figure is mistakenly headed "Figure S2".

Supplemental Table S1. This table is mistakenly headed "Table S3".

Supplemental table S2. This table is mistakenly headed "Table S4".

\section{Study II}

Page 1259 first column fourth paragraph. The date when ethical permission was obtained was 30 March 2011.

Page 1260 second column first paragraph. The line "Only DIs associated with a standard deviation of $\leq 1$ are reported" should be omitted.

Page 1262 Table 2 and main text. In one dehydrated patient invasive $\mathrm{Hb}$ measurements were lost. Thus kinetic data are reported from 19 euhydrated and 10 dehydrated patients.

First column line 5 "averaged 2.8" should read "had a median of 2.8".

Page 1263 first column second line, should read "18 curves". 


\section{REFERENCES}

1 Cannon, Walter B. The wisdom of the body. Rev ed. 1967. W.W. Norton and Co, New York.

2 Barsoum N, Kleeman C. Now and then, the history of parenteral fluid administration. Am J Nephrol 2002;22:284-289.

3 Foëx BA. How the cholera epidemic of 1831 resulted in a new technique for fluid resuscitation. Emerg Med J 2003;20:316-318.

4 Srinivasa S, Hill AG. Perioperative fluid administration: historical highlights and implications for practice. Ann Surg 2012;256:11131118.

5 Rahbari NN, Zimmermann JB, Schmidt T, Koch M, Weigand MA, Weitz J. Meta-analysis of standard, restrictive and supplemental fluid administration in colorectal surgery. Br J Surg 2009;96:331-341.

6 Chan ST, Kapadia CR, Johnson AW, Radcliffe AG, Dudley HA. Extracellular fluid volume expansion and third space sequestration at the site of small bowel anastomoses. Br J Surg 1983;70:36-39.

7 Ince C. Hemodynamic coherence and the rationale for monitoring the microcirculation. Crit Care 2015;19 Suppl 3:S8.

8 Holte K, Foss NB, Andersen J, Valentiner L, Lund C, Bie P et al. Liberal or restrictive fluid administration in fast-track colonic surgery: a randomized, double-blind study. Br J Anaesth 2007;99:500-508.

9 Thacker JK, Mountford WK, Ernst FR, Krukas MR, Mythen MM. Perioperative fluid utilization variability and association with outcomes: considerations for enhanced recovery efforts in sample US surgical populations. Ann Surg 2016;263:502-510.

10 Raymond DP, Seder CW, Wright CD, Magee MJ, Kosinski AS, Cassivi SD et al. Predictors of major morbidity or mortality after resection for esophageal cancer: a Society of Thoracic Surgeons general thoracic surgery database risk adjustment model. Ann Thorac Surg 2016;102:207-214. 
11 Carney A, Dickinson M. Anesthesia for esophagectomy. Anesthesiology Clin 2015;33:143-163.

12 Cecconi M, Corredor C, Arulkumaran N, Abuella G, Ball J, Grounds $\mathrm{RM}$ et al. Clinical review: Goal-directed therapy-what is the evidence in surgical patients? The effect on different risk groups. Crit Care 2013;17:209.

13 Hamilton-Davies C, Mythen MG, Salmon JB, Jacobson D, Shukla A, Webb AR. Comparison of commonly used clinical indicators of hypovolaemia with gastrointestinal tonometry. Intensive Care Med 1997;23:276-281.

14 Marik PE, Cavallazzi R. Does the central venous pressure predict fluid responsiveness? An updated meta-analysis and a plea for some common sense. Crit Care Med 2013;41:1774-1781.

15 Sondergaard S, Parkin G, Aneman A. Central venous pressure: soon an outcome-associated matter. Curr Opin Anaesthesiol 2016;29:179185 .

16 Matot I, Paskaleva R, Eid L, Cohen K, Khalaileh A, Elazary R et al. Effect of the volume of fluids administered on intraoperative oliguria in laparoscopic bariatric surgery: a randomized controlled trial. Arch Surg 2012;147:228-234.

17 van der Zee EN, Egal M, Gommers D, Groeneveld AB. Targeting urine output and 30-day mortality in goal-directed therapy: a systematic review with meta-analysis and meta-regression. BMC Anesthesiol 2017;17:22.

18 Rhodes A, Evans LE, Alhazzani W, Levy MM, Antonelli M, Ferrer R et al. Surviving Sepsis Campaign: International guidelines for management of sepsis and septic shock: 2016. Intensive Care Med 2017;43:304-377.

19 Marik P, Bellomo R. A rational approach to fluid therapy in sepsis. Br J Anaesth 2016;116:339-349.

20 Wenkui Y, Ning L, Jianfeng G, Weiqin L, Shaoqiu T, Zhihui T et al. Restricted peri-operative fluid administration adjusted by serum lactate level improved outcome after major elective surgery for gastrointestinal malignancy. Surgery 2010;147:542-552. 
21 Futier E, Robin E, Jabaudon M, Guerin R, Petit A, Bazin JE et al. Central venous $\mathrm{O}_{2}$ saturation and venous-to-arterial $\mathrm{CO}_{2}$ difference as complementary tools for goal-directed therapy during high-risk surgery. Crit Care. 2010;14(5):R193.

22 van Beest P, Wietasch G, Scheeren T, Spronk P, Kuiper M. Clinical review: use of venous oxygen saturations as a goal - a yet unfinished puzzle. Crit Care 2011;15:232.

23 Perel A. Bench-to-bedside review: the initial hemodynamic resuscitation of the septic patient according to Surviving Sepsis Campaign guidelines--does one size fit all? Crit Care 2008;12:223.

24 Donati A, Loggi S, Preiser JC, Orsetti G, Münch C, Gabbanelli V et al. Goal-directed intraoperative therapy reduces morbidity and length of hospital stay in high-risk surgical patients. Chest 2007;132:18171824 .

25 Mikor A, Trásy D, Németh MF, Osztroluczki A, Kocsi S, Kovács I et al. Continuous central venous oxygen saturation assisted intraoperative hemodynamic management during major abdominal surgery: a randomized, controlled trial. BMC Anesthesiol 2015;15:82.

26 Shoemaker WC, Appel PL, Kram HB, Waxman K, Lee TS. Prospective trial of supranormal values of survivors as therapeutic goals in high-risk. Chest 1988;94;1176-1186.

27 Hamilton MA, Cecconi M, Rhodes A. A systematic review and metaanalysis on the use of preemptive hemodynamic intervention to improve postoperative outcomes in moderate and high-risk surgical patients. Anesth Analg. 2011;112:1392-1402.

28 Roche AM, Miller TE, Gan TJ. Goal-directed fluid management with trans-oesophageal Doppler. Best Pract Res Clin Anaesthesiol 2009;23:327-334.

29 Mayer J, Boldt J, Mengistu AM, Röhm KD, Suttner S. Goal-directed intraoperative therapy based on autocalibrated arterial pressure waveform analysis reduces hospital stay in high-risk surgical patients: a randomized, controlled trial. Crit Care 2010;14:e18.

30 Scott MJ, Baldini G, Fearon KC, Feldheiser A, Feldman LS, Gan TJ et al. Enhanced Recovery After Surgery (ERAS) for gastrointestinal surgery, part 1: pathophysiological considerations. Acta Anaesthesiol Scand 2015;59:1212-1231. 
31 Cuthbertson BH, Campbell MK, Stott SA, Elders A, Hernández R, Boyers D et al. FOCCUS study group. A pragmatic multi-centre randomised controlled trial of fluid loading in high-risk surgical patients undergoing major elective surgery-the FOCCUS study. Crit Care 2011;15:R296.

32 Myles PS, Bellomo R, Corcoran T, Forbes A, Peyton P, Story D et al. Australian and New Zealand College of Anaesthetists Clinical Trials Network and the Australian and New Zealand Intensive Care Society Clinical Trials Group. Restrictive versus liberal fluid therapy for major abdominal surgery. N Engl J Med 2018;378:2263-2274.

33 Hahn RG, Waldréus N. An aggregate urine analysis tool to detect acute dehydration. Int J Sport Nutr Exerc Metab 2013;23:303-311.

34 Hahn RG. Volume kinetics for infusion fluids. Anesthesiology 2010;113:470-481.

35 Landis JR, Koch GG. The measurement of observer agreement for categorical data. Biometrics 1977;33:159-174.

36 Cannesson M, Le Manach Y, Hofer CK, Goarin JP, Lehot JJ, Vallet B et al. Assessing the diagnostic accuracy of pulse pressure variations for the prediction of fluid responsiveness: a "gray zone" approach. Anesthesiology 2011;115:231-241.

37 Benes J, Chytra I, Altmann P, Hluchy M, Kasal E, Svitaket R et al. Intraoperative fluid optimization using stroke volume variation in high risk surgical patients: results of prospective randomized study. Crit Care 2010;14:e118.

38 Tekkis PP, McCulloch P, Poloniecki JD Prytherch DR, Kessaris N, Steger AC. Risk-adjusted prediction of operative mortality in oesophagogastric surgery with O-POSSUM. Br J Surg 2004;91:288295.

39 Bundgaard-Nielsen M, Jørgensen CC, Kehlet H, Secher NH. Normovolemia defined according to cardiac stroke volume in healthy supine humans. Clin Physiol Funct Imaging 2010;30:318-322.

40 Godfrey GEP, Dubrey SW, Handy JM. A prospective observational study of stroke volume responsiveness to a passive leg raise manoeuvre in healthy nonstarved volunteers as assessed by transthoracic echocardiography Anaesthesia 2014;69:306-313. 
41 Minto G, Struthers R. Stroke volume optimisation: is the fairy tale over? Anaesthesia 2014;69:291-296.

42 Gelman S, Bigatello L. The physiologic basis for goal-directed hemodynamic and fluid therapy: the pivotal role of the venous circulation. Can J Anesth 2018;65:294.

43 Morris C. Oesophageal Doppler monitoring, doubt and equipoise: evidence based medicine means change. Anaesthesia 2013;68:677683.

44 Carey JS. Determinants of cardiac output during experimental therapeutic hemodilution. Ann Surg 1975;181:196-202.

45 Fowler NO, Holmes JC. Blood viscosity and cardiac output in acute experimental anemia. J Appl Physiol 1975;39:453-456.

46 Minto G, Scott MJ, Miller TE. Monitoring needs and goal-directed fluid therapy within an enhanced recovery program. Anesthesiol Clin 2015;33:35-49.

47 Prather JW, Taylor AE, Guyton AC. Effect of blood volume, mean circulatory pressure, and stress relaxation on cardiac output. Am J Physiol 1969;216:467-472.

48 Bada AA, Svendsen JH, Secher NH, Saltin B, Mortensen SP. Peripheral vasodilatation determines cardiac output in exercising humans: insight from atrial pacing. J Physiol 2012;590:2051-2060.

49 Wolff CB. Normal cardiac output, oxygen delivery and oxygen extraction. Adv Exp Med Biol 2007;599:169-182.

50 Aya HD, Ster IC, Fletcher N, Grounds RM, Rhodes A, Cecconi M. Pharmacodynamic analysis of a fluid challenge. Crit Care Med 2016;44:880-891.

51 Challand C, Struthers R, Sneyd JR, Erasmus PD, Mellor N, Hosie KB et al. Randomized controlled trial of intraoperative goal-directed fluid therapy in aerobically fit and unfit patients having major colorectal surgery. Br J Anaesth 2012;108:53-62.

52 Hahn, RG. Body volumes and fluid kinetics. In Hahn RG (ed), Clinical Fluid Therapy in the Perioperative Setting. Cambridge University Press, Cambridge, UK, 2nd ed, p 47. 
53 Boer C, Bossers SM, Koning NJ. Choice of fluid type: physiological concepts and perioperative indications. Br J Anaesth 2018;120:384396.

54 Sondergaard S. Pavane for a pulse pressure variation defunct. Crit Care 2013;17:327.

55 Michard F. Changes in arterial pressure during mechanical ventilation. Anesthesiology 2005;103:419-428.

56 De Backer D, Heenen S, Piagnerelli M, Koch M, Vincent JL. Pulse pressure variations to predict fluid responsiveness: influence of tidal volume. Intensive Care Med 2005;31:517-523.

57 Maguire S, Rinehart J, Vakharia S, Cannesson M. Technical communication: respiratory variation in pulse pressure and plethysmographic waveforms: intraoperative applicability in a North American academic center. Anesth Analg 2011;112:94-96.

58 Julien F, Hilly J, Sallah TB, Skhiri A, Michelet D, Brasher C et al. Plethysmographic variability index (PVI) accuracy in predicting fluid responsiveness in anesthetized children. Paediatr Anaesth 2013;23:536-546.

59 Marik PE. Obituary: pulmonary artery catheter 1970 to 2013. Ann Intensive Care 2013;3:38.

60 Meng L, Tran NP, Alexander BS, Laning K, Chen G, Kain ZN et al. The impact of phenylephrine, ephedrine, and increased preload on third-generation Vigileo-FloTrac and esophageal doppler cardiac output measurements. Anesth Analg 2011;113:751-757.

61 Bergek C, Zdolsek JH, Hahn RG. Non-invasive blood haemoglobin and plethysmographic variability index during brachial plexus block. Br J Anaesth 2015;114:812-817.

62 Panza JA Epstein SE, Quyyumi AA. Circadian variation in vascular tone and its relation to alpha-sympathetic vasoconstrictor activity. $\mathrm{N}$ Engl J Med 1991;325:986-990.

63 Cogliati C, Magatelli R, Montano N, Narkiewicz K, Somers VK. Detection of low- and high-frequency rhythms in the variability of skin sympathetic nerve activity. Am J Physiol Heart Circ Physiol 2000;278:H1256-1260. 
64 Biais M, Cottenceau V, Petit L, Masson F, Cochard JF, Sztark F. Impact of norepinephrine on the relationship between pleth variability index and pulse pressure variations in ICU adult patients. Crit Care 2011;15:R168.

65 Hahn RG, Li Y, Zdolsek J. Non-invasive monitoring of blood haemoglobin for analysis of fluid volume kinetics. Acta Anaesthesiol Scand 2010;54:1233-1240.

66 Zhang J, Critchley LA, Huang L. The effect of aorta unfolding and remodelling on oesophageal Doppler readings as probe depth is varied. Br J Anaesth 2015;115:708-715.

67 Schober P, Loer SA, Schwarte LA. Transesophageal Doppler devices: A technical review. J Clin Monit Comput 2009;23:391-401.

68 Pauca AL, Wallenhaupt SL, Kon ND. Reliability of the radial arterial pressure during anesthesia. Is wrist compression a possible diagnostic test? Chest 1994;105:69-75.

69 Smith J, Camporota L, Beale R. Monitoring arterial blood pressure and cardiac output using central or peripheral arterial pressure waveforms. In: Vincent JL (ed), Yearbook of intensive care and emergency medicine. Heidelberg: Springer; 2009. p. 285-296.

70 Feltracco P, Biancofiore G, Ori C, Saner FH, Della Rocca G. Limits and pitfalls of haemodynamic monitoring systems in liver transplantation surgery. Minerva Anestesiol 2012;78:1372-1384.

71 Hofer CK, Button D, Weibel L, Genoni M, Zollinger A. Uncalibrated radial and femoral arterial pressure waveform analysis for continuous cardiac output measurement: an evaluation in cardiac surgery patients. J Cardiothorac Vasc Anesth 2010;24:257-264.

72 Maddali MM, Waje ND, Sathiya PM. Authentication of radial versus femoral arterial pressure waveform-derived cardiac output with transesophageal echocardiography-derived cardiac output measurements in patients undergoing on-pump coronary bypass surgery. $\mathrm{J}$ Cardiothorac Vasc Anesth 2017;31:1183-1189.

73 Pavlovic G, Diaper J, Ellenberger C, Frei A, Bendjelid K, Bonhomme $\mathrm{F}$ et al. Impact of early haemodynamic goal-directed therapy in patients undergoing emergency surgery: an open prospective, randomised trial. J Clin Monit Comput 2016;30:87-99. 
74 Reyad AR, Elkharboutly W, Wahba A,Elmorshedi M, Hasaneen NA. Effect of intraoperative dobutamine on splanchnic tissue perfusion and outcome after Whipple surgery. J Crit Care 2013;28:531.

75 Davies SJ, Yates D, Wilson RJ. Dopexamine has no additional benefit in high-risk patients receiving goal-directed fluid therapy undergoing major abdominal surgery. Anesth Analg 2011;112:130-138.

76 Takala J, Meier-Hellmann A, Eddleston J, Hulstaert P, Sramek V. Effect of dopexamine on outcome after major abdominal surgery: a prospective, randomized, controlled multicenter study. European Multicenter Study Group on Dopexamine in Major Abdominal Surgery. Crit Care Med 2000;28:3417-3423.

77 Wuethrich PY, Burkhard FC, Thalmann GN, Stueber F, Studer UE. Restrictive deferred hydration combined with preemptive norepinephrine infusion during radical cystectomy reduces postoperative complications and hospitalization time: a randomized clinical trial. Anesthesiology 2014;120:365-377.

78 Durkin C, Schisler T, Lohser J. Current trends in anesthesia for esophagectomy. Curr Opin Anaesthesiol 2017;30:30-35.

79 Glatz T, Kulemann B, Marjanovic G, Bregenzer S, Makowiec F, Hoeppner J. Postoperative fluid overload is a risk factor for adverse surgical outcome in patients undergoing esophagectomy for esophageal cancer: a retrospective study in 335 patients. BMC Surg 2017;17:6.

80 Ylinenvaara SI, Elisson O, Berg K, Zdolsek JH, Krook H, Hahn RG. Preoperative urine-specific gravity and the incidence of complications after hip fracture surgery: A prospective, observational study. Eur J Anaesthesiol 2014;31:85-90.

81 Ellis RJ, Del Vecchio SJ, Kalma B, Ng KL, Morais C, Francis RS et al. Association between preoperative hydration status and acute kidney injury in patients managed surgically for kidney tumours. Int Urol Nephrol 2018;50:1211-1217.

82 Jacob M, Chappell D, Conzen P, Finsterer U, Rehm M. Blood volume is normal after pre-operative overnight fasting. Acta Anaesthesiol Scand 2008;52:522-529. 
83 Pearse RM, Harrison DA, MacDonald N, Gillies MA, Blunt M, Ackland $\mathrm{G}$ et al. Effect of a perioperative, cardiac output-guided hemodynamic therapy algorithm on outcomes following major gastrointestinal surgery: a randomized clinical trial and systematic review. JAMA 2014;311:2181-2190.

84 Grocott MP, Dushianthan A, Hamilton MA, Mythen MG, Harrison D, Rowan K. Perioperative increase in global blood flow to explicit defined goals and outcomes after surgery: a Cochrane systematic review. Br J Anaesth 2013;111:535-548.

85 Som A, Maitra S, Bhattacharjee S, Baidya DK. Goal directed fluid therapy decreases postoperative morbidity but not mortality in major non-cardiac surgery: a meta-analysis and trial sequential analysis of randomized controlled trials. J Anesth 2017;31:66-81.

86 Michard F, Giglio M, Brienza N. Perioperative goal-directed therapy with uncalibrated pulse contour methods: impact on fluid management and post-operative outcome. Br J Anaesth 2017;119:22-30.

87 Chong MA, Wang Y, Berbenetz NM, McConachie I. Does goaldirected haemodynamic and fluid therapy improve peri-operative outcomes?: A systematic review and meta-analysis. Eur J Anaesthesiol 2018;35:469-483.

88 Rollins KE, Lobo DN. Intraoperative goal-directed fluid therapy in elective major abdominal surgery: A meta-analysis of randomized controlled trials. Ann Surg 2016;263:465-476.

89 Wilson RTJ, Minto G. The great fluid debate: time for Flexit? Br J Anaesth 2017;118:819-822.

90 Murray D. What should we do when traditional research fails? Anaesthesia 2017;72:1055-1068.

91. Edwards MR, Forbes G, MacDonald N, Berdunov V, Mihaylova B, Dias P et al. OPTIMISE II investigators. Optimisation of Perioperative Cardiovascular Management to Improve Surgical Outcome II (OPTIMISE II) trial: study protocol for a multicentre international trial of cardiac output-guided fluid therapy with low-dose inotrope infusion compared with usual care in patients undergoing major elective gastrointestinal surgery. BMJ Open 2019;9:e023455 
92 Varadhan KK, Lobo DN. A meta-analysis of randomised controlled trials of intravenous fluid therapy in major elective open abdominal surgery: getting the balance right. Proc Nutr Soc 2010;69:488-498.

93 Shin CH, Long DR, McLean D, Grabitz SD, Ladha K, Timm FP et al. Effects of intraoperative fluid management on postoperative outcomes: A hospital registry study. Ann Surg 2018;267:1084-1092.

94 Bundgaard-Nielsen M, Holte K, Secher NH, Kehlet H. Monitoring of peri-operative fluid administration by individualized goal-directed therapy. Acta Anaesthesiol Scand 2007;51:331-340.

95 Rollins KE, Lobo DN. Intraoperative goal-directed fluid therapy in elective major abdominal surgery: A meta-analysis of randomized controlled trials. Ann Surg 2016;263:465-476.

96 Brandstrup B, Svendsen PE, Rasmussen M, Belhage B, Rodt SÅ, HansenB et al. Which goal for fluid therapy during colorectal surgery is followed by the best outcome: near-maximal stroke volume or zero fluid balance? Br J Anaesth 2012;109:191-199.

97 Colantonio L, Claroni C, Fabrizi L, Marcelli ME, Sofra M, Giannarelli $\mathrm{D}$ et al. A randomized trial of goal directed vs. standard fluid therapy in cytoreductive surgery with hyperthermic intraperitoneal chemotherapy. J Gastrointest Surg 2015;19:722-729.

98 Broch O, Bein B, Gruenewald M, Höcker J, Schöttler J, Meybohm P et al. Accuracy of the pleth variability index to predict fluid responsiveness depends on the perfusion index. Acta Anaesthesiol Scand 2011;55:686-693.

99 Desgranges FP, Desebbe O, Ghazouani A, Gilbert K, Keller G, Chiari $\mathrm{P}$ et al. Influence of the site of measurement on the ability of plethysmographic variability index to predict fluid responsiveness. Br J Anaesth 2011;107:329-335.

100 Fischer MO, Pellissier A, Saplacan V, Gérard JL, Hanouz JL, Fellahi JL. Cephalic versus digital plethysmographic variability index measurement: a comparative pilot study in cardiac surgery patients. $\mathbf{J}$ Cardiothorac Vasc Anesth 2014;28:1510-1515.

101 Desebbe O, Boucau C, Farhat F, Bastien O, Lehot J-J, Cannesson M. The ability of pleth variability index to predict the hemodynamic effects of positive end-expiratory pressure in mechanically ventilated patients under general anesthesia. Anesth Analg 2010;110:792-798. 
102 Futier E, Constantin J-M, Paugam-Burtz C, Pascal J, Eurin M, Neuschwander A et al. IMPROVE Study Group. A trial of intraoperative low-tidal-volume ventilation in abdominal surgery. $\mathrm{N}$ Engl $\mathrm{J}$ Med 2013;369:428-437.

103 Critchley LA, Yang XX, Lee A. Assessment of trending ability of cardiac output monitors by polar plot methodology. J Cardiothorac Vasc Anesth 2011;25:536-546.

104 Lesaffre E. Superiority, equivalence, and non-inferiority trials. Bull NYU Hosp Jt Dis. 2008;66:150-154.

105 Greene CJ, Morland LA, Durkalski VL, Frueh BC. Noninferiority and equivalence designs: issues and implications for mental health research. J Trauma Stress 2008;21:433-439.

106 Dunn DT, Copas AJ, Brocklehurst P. Superiority and non-inferiority: two sides of the same coin? Trials 2018;19:499.

107 Brandstrup B, Tønnesen H, Beier-Holgersen R, Hjortsø E, Ørding H, Lindorff-Larsen $\mathrm{K}$ et al. Effects of intravenous fluid restriction on postoperative complications: comparison of two perioperative fluid regimens: a randomized assessor-blinded multicenter trial. Ann Surg 2003;238:641-648.

108 Mascha EJ, Sessler DI. Design and analysis of studies with binaryevent composite endpoints: guidelines for anesthesia research. Anesth Analg 2011;112:1461-1471.

109 Cooke K, Sharvill R, Sondergaard S, Aneman A. Volume responsiveness assessed by passive leg raising and a fluid challenge: a critical review focused on mean systemic filling pressure. Anaesthesia 2018;73:313-322. 


\section{APPENDIX}

Table 1. Definition of complications used in Study III

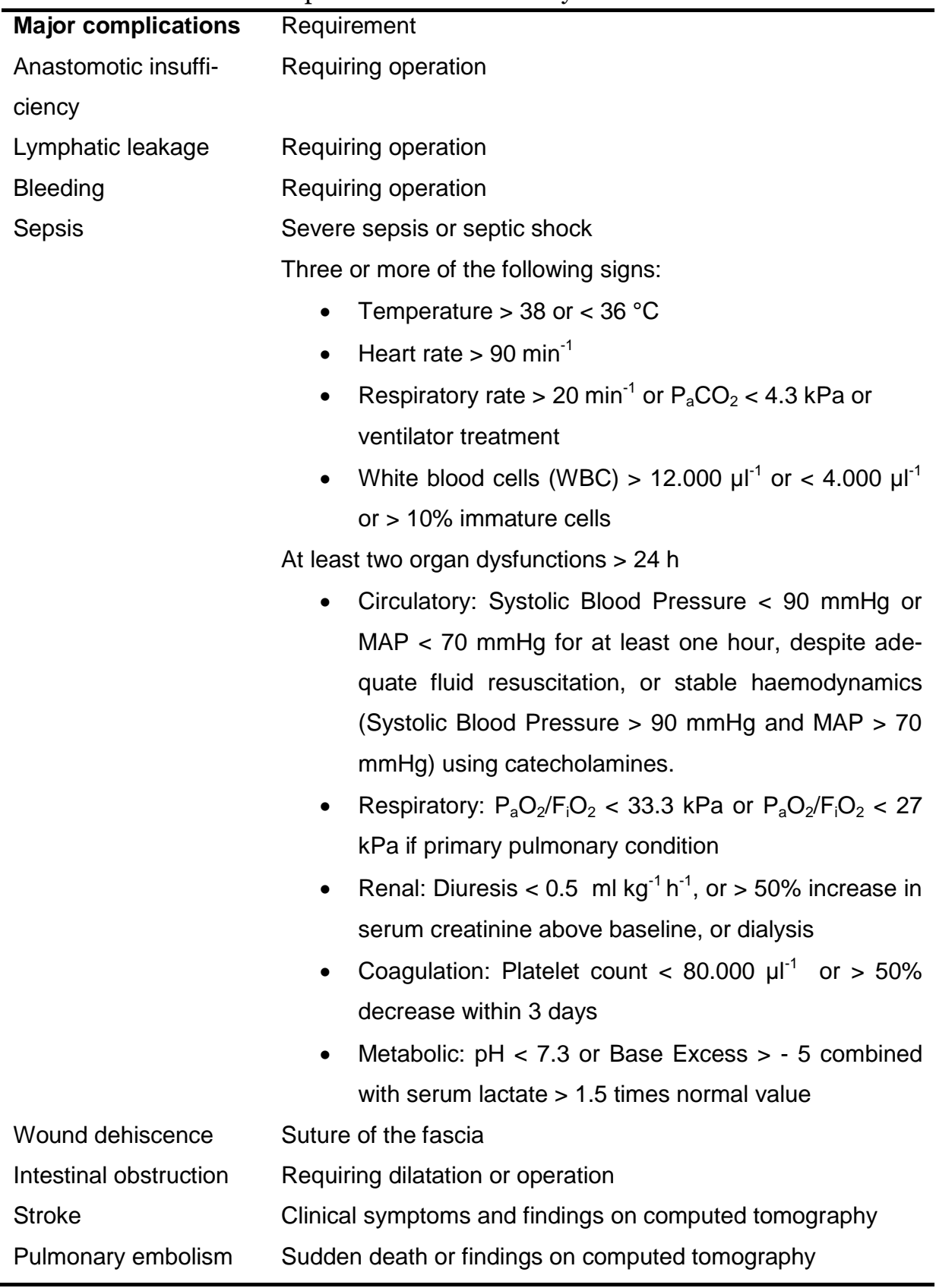




\begin{tabular}{|c|c|}
\hline Deep vein thrombosis & Requiring treatment, without pulmonary embolism \\
\hline $\begin{array}{l}\text { Pulmonary oedema / } \\
\text { respiratory insufficien- } \\
\text { cy / pneumonia }\end{array}$ & $\begin{array}{l}\text { Ventilator treatment or Continuous Positive Airway Pressure } \\
\text { (CPAP) / Non-Invasive Ventilation (NIV) not exclusively for } \\
\text { prophylaxis of atelectasis }\end{array}$ \\
\hline Pleural effusion & Drainage \\
\hline Myocardial infarction & $\begin{array}{l}\text { 1. Increase in serum levels of high-sensitivity Troponin } T \\
\text { above } 15 \mathrm{ng} \mathrm{I}^{-1} \text {, and an increasing or decreasing trend in } \\
\text { these serum levels based on at least two samples with at } \\
\text { least a } 6 \text {-hour interval, and at least one of the following: } \\
\text { a. Typical symptoms: Typical chest pain for at least } 15 \\
\text { minutes or pulmonary edema without any other cause. } \\
\text { b. ECG changes: Appearance of pathological Q-waves (dura- } \\
\text { tion > } 0.03 \text { sec and }>25 \% \text { of R-wave amplitude) in at least } 2 \\
\text { leads, or ischaemic ST-changes or appearance of left bundle } \\
\text { branch block (LBBB). } \\
\text { c. Imaging studies showing recent loss of viable myocardium } \\
\text { or appearance of regional wall motion abnormality, } \\
\text { or } \\
2 \text {. Typical symptoms and ST increase / new LBBB / new } \\
\text { thrombus as seen on coronary angiography and no possibility } \\
\text { for further work-up because of sudden death. }\end{array}$ \\
\hline Arrhythmia & Requiring medical treatment or electro-conversion \\
\hline Cardiac arrest & Cardiopulmonary resuscitation \\
\hline Renal dysfunction & $\begin{array}{l}\text { Diuresis }<500 \mathrm{ml} 24 \mathrm{~h}^{-1},>30 \% \text { increase in serum creatinine } \\
\text { compared to baseline }\end{array}$ \\
\hline
\end{tabular}

Liver dysfunction Serum bilirubin $>100 \mu \mathrm{mol} \mathrm{I}^{-1}$ and prothrombin time (international normalised ratio) $(\mathrm{PT}(\mathrm{INR}))>1.6$

\section{Minor Complications}

Superficial wound in- Local inflammatory signs and specific antibiotic treatment fection or dehiscence

Infection

Paralytic ileus

Fever and new antibiotic treatment not qualifying as sepsis

Upper Gl bleeding

$>7$ days without flatus

Pulmonary congestion

Clinical and/or endoscopic signs and specific treatment

Dyspnoea and auscultatory findings compatible with pulmonary congestion, and pharmacological treatment 


\begin{tabular}{ll}
\hline Angina pectoris & Pharmacological treatment \\
Hypotension & Requiring pharmacological treatment $>12 \mathrm{~h}$ \\
Delirium & Requiring intervention \\
Coagulopathy & Platelet count $<100.000 \mu \mathrm{l}^{-1}, \mathrm{PT}(\mathrm{INR})>1.6$, activated partial \\
& thromboplastin time $>50 \mathrm{~s}$ \\
Severe postoperative & Nausea and/or vomiting limiting mobilisation, and/or requiring \\
nausea and vomiting & iv fluids, and/or causing prolonged length of stay \\
Urinary retention & Urinary retention requiring catheter (excluding catheter as \\
& required by local protocol) \\
\hline
\end{tabular}


Table 2. Definition of complications used in Study IV

\begin{tabular}{|c|c|}
\hline Major complications & Requirement \\
\hline $\begin{array}{l}\text { Anastomotic insuffi- } \\
\text { ciency }\end{array}$ & Requiring operation \\
\hline Lymphatic leakage & Requiring operation \\
\hline Bleeding & Requiring operation \\
\hline \multirow[t]{8}{*}{ Sepsis } & Severe sepsis or septic shock \\
\hline & $\begin{array}{l}\text { Three or more of the following signs: } \\
\text { - Temperature }>38 \text { or }<36{ }^{\circ} \mathrm{C} \\
\text { - Heart rate }>90 \mathrm{~min}^{-1} \\
\text { - } \text { Respiratory rate }>20 \mathrm{~min}^{-1} \text { or } \mathrm{P}_{\mathrm{a}} \mathrm{CO}_{2}<4.3 \mathrm{kPa} \text { or } \\
\text { ventilator treatment } \\
\text { - } \mathrm{WBC}>12.000 \mathrm{\mu l}^{-1} \text { or }<4.000 \mu \mathrm{l}^{-1} \text { or }>10 \% \text { immature } \\
\text { cells }\end{array}$ \\
\hline & At least two organ dysfunctions $>24 \mathrm{~h}$ \\
\hline & $\begin{array}{l}\text { - Circulatory: Systolic Blood Pressure }<90 \mathrm{mmHg} \text { or } \\
\mathrm{MAP}<70 \mathrm{mmHg} \text { for at least one hour, despite ade- } \\
\text { quate fluid resuscitation, or stable haemodynamics } \\
\text { (Systolic Blood Pressure }>90 \mathrm{mmHg} \text { and MAP }>70 \\
\mathrm{mmHg} \text { ) using catecholamines. }\end{array}$ \\
\hline & $\begin{array}{l}\text { - Respiratory: } \mathrm{P}_{\mathrm{a}} \mathrm{O}_{2} / \mathrm{F}_{\mathrm{i}} \mathrm{O}_{2}<33.3 \mathrm{kPa} \text { or } \mathrm{P}_{\mathrm{a}} \mathrm{O}_{2} / \mathrm{F}_{\mathrm{i}} \mathrm{O}_{2}<27 \\
\mathrm{kPa} \text { if primary pulmonary condition }\end{array}$ \\
\hline & $\begin{array}{l}\text { - Renal: Diuresis }<0.5 \mathrm{ml} \mathrm{kg}^{-1} \mathrm{~h}^{-1} \text {, or }>50 \% \text { increase in } \\
\text { serum creatinine above baseline, or dialysis }\end{array}$ \\
\hline & $\begin{array}{l}\text { - Coagulation: Platelet count }<80.000 \mu^{-1} \text { or }>50 \% \\
\text { decrease within } 3 \text { days }\end{array}$ \\
\hline & $\begin{array}{l}\text { - Metabolic: } \mathrm{pH}<7.3 \text { or Base Excess }>-5 \text { combined } \\
\text { with serum lactate }>1.5 \text { times normal value }\end{array}$ \\
\hline Wound dehiscence & Suture of the fascia \\
\hline Intestinal obstruction & Requiring dilatation or operation \\
\hline Stroke & Clinical symptoms and findings on computed tomography \\
\hline Pulmonary embolism & Sudden death or findings on computed tomography \\
\hline $\begin{array}{l}\text { Pulmonary oedema / } \\
\text { respiratory insufficien- } \\
\text { cy / pneumonia }\end{array}$ & $\begin{array}{l}\text { Ventilator treatment or CPAP / NIV not exclusively for } \\
\text { prophylaxis of atelectasis }\end{array}$ \\
\hline
\end{tabular}




\begin{tabular}{|c|c|}
\hline Myocardial infarction & $\begin{array}{l}\text { 1. Increase in serum levels of high-sensitivity Troponin T } \\
\text { above } 15 \mathrm{ng} \mathrm{I}^{-1} \text {, and an increasing or decreasing trend in } \\
\text { these serum levels based on at least two samples with at } \\
\text { least a } 6 \text {-hour interval, and at least one of the following: } \\
\text { a. Typical symptoms: Typical chest pain for at least } 15 \\
\text { minutes or pulmonary oedema without any other cause } \\
\text { b. ECG changes: Appearance of pathological Q-waves (dura- } \\
\text { tion > } 0.03 \text { sec and > } 25 \% \text { of R-wave amplitude) in at least } 2 \\
\text { leads, or ischaemic ST-changes or appearance of LBBB } \\
\text { c. Imaging studies showing recent loss of viable myocardium } \\
\text { or appearance of regional wall motion abnormality, } \\
\text { or } \\
2 \text {. Typical symptoms and ST increase / new LBBB / new } \\
\text { thrombus as seen on coronary angiography and no possibility } \\
\text { for further work-up because of sudden death }\end{array}$ \\
\hline $\begin{array}{l}\text { Bradycardia / ventricu- } \\
\text { lar arrhythmia }\end{array}$ & Requiring medical treatment or electro-conversion \\
\hline Hypotension & Requiring pharmacological treatment $>24 \mathrm{~h}$ \\
\hline Renal failure & Requiring dialysis \\
\hline Minor Complications & \\
\hline $\begin{array}{l}\text { Superficial wound in- } \\
\text { fection or dehiscence }\end{array}$ & Local inflammatory signs and specific antibiotic treatment \\
\hline Paralytic ileus & $>7$ days without flatus \\
\hline Pulmonary congestion & $\begin{array}{l}\text { Dyspnoea and auscultatory findings compatible with pulmo- } \\
\text { nary congestion, and pharmacological treatment }\end{array}$ \\
\hline Atelectasis & Requiring treatment with CPAP / NIV \\
\hline Pneumonia & Fever or infiltrate on chest X-ray and antibiotic treatment \\
\hline Other infection & Fever and new antibiotic treatment not qualifying as sepsis \\
\hline Pleural effusion & Drainage \\
\hline Minor arrythmia & Requiring intervention \\
\hline Delirium & Requiring intervention \\
\hline Deep vein thrombosis & Requiring treatment, without pulmonary embolism \\
\hline Renal dysfunction & $\begin{array}{l}\text { Diuresis }<500 \mathrm{ml} 24 \mathrm{~h}^{-1},>30 \% \text { increase in serum creatinine } \\
\text { compared to baseline }\end{array}$ \\
\hline Coagulopathy & Platelet count $<100.000 \mu l^{-1}$, PT $($ INR $)>1.6$, APTT $>50 \mathrm{~s}$ \\
\hline
\end{tabular}




\section{STUDIES I-IV}




\section{Papers}

The papers associated with this thesis have been removed for copyright reasons. For more details about these see:

http://urn.kb.se/resolve?urn=urn:nbn:se:liu:diva-156263 


\section{FACULTY OF MEDICINE AND HEALTH SCIENCES}

Linköping University Medical Dissertations No 1665, 2019 Department of Medical and Health Sciences

Linköping University

SE-581 83 Linköping, Sweden

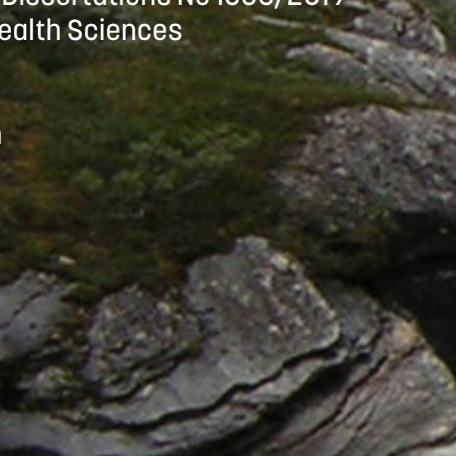

\section{www.liu.se}

